\title{
LOS VENEROS DEL EMPERADOR. IMPULSO PETROLERO GLOBAL, INTERESES Y POLÍTICA DEL PETRÓLEO EN MÉXICO DURANTE EL SEGUNDO IMPERIO, 1863-1867
}

\author{
Paolo Riguzzi \\ El Colegio Mexiquense \\ Francesco Gerali \\ University of Western Australia
}

[...] la sustancia bituminosa conocida como petróleo, que tanto abunda en el país sin provecho ni objeto para el mismo (1865)

\section{INTRODUCCIÓN}

Wéxico representa un caso de activación tardía de la 1 industria petrolera, con una brecha temporal considerable entre la existencia conocida de fuentes de hidrocarburos

Fecha de recepción: 7 de enero de 2015

Fecha de aceptación: 20 de abril de 2015

${ }^{1}$ Agradecemos los comentarios de Sandra Kuntz Ficker a una versión preliminar, las preguntas de Antonia Pi Suñer y las sugerencias bibliográficas que nos brindaron Ana Buriano y Antonio Escobar Ohmstede. 
y el desarrollo de la actividad extractiva, que se verificó solo a comienzos del siglo xx. La dimensión histórica de la brecha tiene como punto de partida los inicios de la década de 1860, momento en el cual en Estados Unidos surgió la explotación moderna del petróleo, y cuando se desprendió un impulso de corte global, propagado por el choque tecnológico y comercial ligado a la experiencia estadounidense de extracción masiva y refinación del crudo.

En este marco se generó el despertar del interés por el petróleo en México, durante el efímero gobierno imperial de Maximiliano de Habsburgo. Entre 1864 y 1865, tomó forma una "manía” petrolera en México, alimentada por intereses tanto públicos como privados, y se verificó una ola de localización y denuncios de terrenos petrolíferos; al mismo tiempo, se intentó establecer los lineamientos de una política al respecto. Se trató de una serie de disposiciones que, por primera vez, intentaron normar el uso del crudo, con el objetivo de fomentar su explotación comercial y regular el acceso a él. Fue un paréntesis breve, porque las circunstancias de la guerra civil inhibieron desarrollos operativos; los republicanos, tras su triunfo, abrogaron las disposiciones del Imperio y la cuestión perdió relieve. La historiografía no ha prestado atención a este momento de la historia de los hidrocarburos en México, y el conocimiento al respecto es muy reducido y anecdótico. ${ }^{2}$ Creemos, en cambio, que lejos de representar

2 Tanto en el amplio estudio de Brown, Petróleo, p. 22, como en ÁlvaREz, Crónica, p. 16, solo se dedican unas líneas a este periodo. Y en lo que se considera el primer informe científico sobre el petróleo hecho en México, el que escribió en 1902 el ingeniero Juan Villarello para el Instituto Geológico Mexicano, no hay mención de actividades anteriores a los años setenta del siglo xix. Villarello, Algunas, pp. 9-11. 
un antecedente arcaico y curioso, esta etapa fue relevante por poner, por primera vez, al petróleo en la agenda económica nacional, y por las consecuencias que esto acarreó. Su estudio nos acerca a la identificación de los obstáculos existentes en México para la explotación del energético, capaces de incidir en el surgimiento de la brecha respecto al desarrollo de la industria petrolera internacional.

El propósito de este trabajo es explicar este auge del interés por el petróleo a mediados de la década de 1860 y medir sus principales manifestaciones así como sus alcances. En particular, consideramos necesario distinguir entre los impulsos procedentes del exterior, las medidas promulgadas por Maximiliano y sus efectos, así como los intereses y las expectativas de los actores domésticos ante la oportunidad del petróleo, sobre todo en cuanto a la concreción de proyectos de inversión. Al mismo tiempo, evaluaremos el papel que este episodio tuvo en el proceso de otorgamiento de un significado comercial al petróleo mexicano. ${ }^{3}$

\section{LOS ANTECEDENTES DEL PETRÓLEO EN MÉXICO}

El petróleo en México, en su calidad de recurso natural, cuenta con una larga historia. Tanto en las civilizaciones prehispánicas, como durante el régimen colonial español, se utilizaron los petróleos - entendidos como bitúmenes líquidos y sólidos - en su estado natural o moldeados mediante el calor. Al igual que en otros países, el petróleo, conocido como chapopote, fue empleado como pegamento, aislante,

3 En el sentido de la transformación de un recurso latente en una mercancía. Black, Crude Reality, pp. 11-12, 20. 
combustible, cosmético y medicina. La corona española importó a Europa chapopote mexicano (así como brea peruana), pero este comercio era reducido en cantidad y limitado a la península Ibérica. ${ }^{4}$ Por otra parte, al igual que en algunas áreas de Canadá y Estados Unidos, al petróleo se le consideraba un peligro para los pozos de agua y de sal; en México las grandes chapopoteras causaban la pérdida de mucho ganado, engullido en las pozas de betún semidenso.

Las chapopoteras se pueden considerar el símbolo histórico del petróleo en México; ningún otro país dispone, en su territorio, de una concentración tan elevada de pozas y lagunas de dimensiones variables, desde decenas hasta centenares de metros cuadrados de superficie. ${ }^{5}$ No obstante la gran disponibilidad de la materia prima, ello no fue suficiente para estimular el uso, el comercio o el estudio del petróleo de forma significativa. Durante los primeros 40 años de vida independiente, ni la comunidad científica ni los gobernantes ni los empresarios habían prestado atención a la cuestión del petróleo. Pese a que se conocieran ciertas aplicaciones útiles, al petróleo durante mucho tiempo no se le consideró importante, por ser una materia de fácil sustitución, ${ }^{6}$ debido a que la frontera tecnológica restringía su uso principal a la iluminación, además de los usos artesanales ya mencionados arriba.

4 Mazadiego Martínez et al., “Information”, 2011; Gerali, “Environmant”, 2013; SÁnchez Graillet, "Del chapopote”.

5 María C. Rosano Hernández, "El chapopote y las chapopoteras del Golfo de México. Crónica sobre el descubrimiento y uso del petróleo”, manuscrito en la biblioteca de El Colegio de México, 2006; Gerali y Riguzzi, "Entender".

6 Iluminantes, lubricantes y disolventes se obtuvieron a partir de una variedad de fuentes, tales como el aceite de la manteca de cerdo o de ballena, el alcohol de los productos agrícolas y la esencia de trementina de la madera. 
Las únicas referencias disponibles a acciones relacionadas con los hidrocarburos indican que en la exposición internacional de París, en 1855, la delegación del Departamento de Veracruz llegó a exhibir "bitúmenes de la región" y que hubo unas cuantas solicitudes de explotación, en el norte de Veracruz y de Puebla. ${ }^{7}$ Pero no hay mención de petróleo o afines en el gran Atlas geográfico, estadístico e histórico, publicado en 1858 por el geógrafo García Cubas, ni en la Estadística general de Pérez Hernández, de 1862. Cuando la Sociedad Mexicana de Geografía y Estadística decidió formar una comisión de expertos para elaborar memorias estadísticas y hacer el "Cuadro sinóptico de la República Mexicana” y de sus riquezas, el petróleo tampoco apareció en el esquema clasificatorio de los recursos de la República. ${ }^{8}$

Desde el punto de vista jurídico, la explotación del petróleo estaba sujeta a las Ordenanzas de Minería de 1783, dictadas por Carlos III, que establecían la propiedad de la corona sobre el subsuelo y la concesión en dominio útil a los particulares

7 Con base en un expediente del AGN, pero sin especificar la fecha, CANUDAS, Venas, 2005, t. II, p. 1146, describe el denuncio pionero del estadounidense A. Jonan, en la laguna de Gila, del distrito de Pánuco, que coincide probablemente con uno de los registrados en 1858 en la misma zona, según MeAde, La Huasteca, t. II, p. 129. La mención de los bitúmenes veracruzanos en la exposición de París, está en Siglo Diez y Nueve (3 sep. 1855), p. 2. En la Memoria de Fomento de 1857, se habla del hallazgo de asfalto en la zona de Teziutlán, Puebla; y en 1861, Pedro Scapini y Compañía declararon ser los descubridores y poseedores de las minas de betún asfáltico en la Mesa de San Diego (norte de Puebla) y Mecatepec (Papantla): Secretaría DE Fomento, Memoria, p. 118, doc. 42; Siglo Diez y Nueve (24 jun. 1861), p. 2. 8 García Cubas, Atlas; Pérez Hernández, Estadística. Entre los 63 rubros de la clasificación de los recursos hecha por la Sociedad no aparecían ni petróleo ni hidrocarburos. Boletín de la Sociedad, t. VIII, 1860, pp. 349-351. 
mediante el mecanismo del denuncio. ${ }^{9}$ Su vigencia se mantuvo durante las primeras seis décadas del México independiente, haciendo del estado el titular del principio regalista que reservaba al soberano el dominio radical sobre el subsuelo y la facultad de conceder la posesión. En las Ordenanzas, sin embargo, no había un reconocimiento específico del petróleo como un recurso mineral, sino que se incluía en la categoría genérica y preindustrial de "bitúmenes y jugos de la tierra". ${ }^{10}$

\section{EL ESCENARIO INTERNACIONAL:}

ESTADOS UNIDOS Y EL IMPULSO PETROLERO “GLOBAL”

Los años sesenta del siglo xix fueron un momento de cambio acelerado y radical en la importancia económica del petróleo, que detonó el modelo de explotación comercial en gran escala. ${ }^{11}$

${ }^{9}$ El denuncio era un procedimiento para adquirir el derecho de trabajar una mina, tanto descubierta como abandonada por poseedores previos. Se basaba en la presentación de una solicitud escrita a la Diputación de Minería del lugar, la que se encargaría de publicarla para averiguar que no se lesionaran derechos preexistentes, y en el lapso de 90 días se realizaría una visita de inspección a la mina a fin de comprobar que el denunciante hubiera llevado a cabo ciertas labores preliminares. Agotado el trámite, se daba valor legal al denuncio. Artículos 4 y 8 del Título Sexto de las Ordenanzas de Minería. Véase la excelente edición de González, Ordenanzas, pp. 217-227. 10 Artículo 22 del Título sexto de las Ordenanzas de Minería. En el México independiente, en las regiones en donde no existía la Diputación de Minería, el denuncio tenía que realizarse ante las autoridades locales y, en régimen federal, ante los gobernadores estatales. Este era el caso de Veracruz, Tamaulipas, Tabasco, entidades con presencia de chapopote, pero con actividades mineras marginales.

${ }^{11}$ En las dos décadas anteriores algunas empresas comerciales producían petróleo del tratamiento de carbón, asfalto, alquitrán de carbón y esquisto, pero sólo en cantidades limitadas y mediante un costoso procedimiento de destilación. Forbes, Studies, pp. 186, 193. 
Tras el descubrimiento de Edwin Laurentine Drake en agosto de 1859 en Titusville, Pennsylvania, la producción de los pozos estadounidenses (en su mayoría de aquel estado y, en menor medida, de Nueva York) tuvo una expansión extraordinaria en unos cuantos años, que tiene pocos iguales en la historia de la explotación de recursos naturales. No por casualidad, la prensa estadounidense comparó este surgimiento tan súbito de riqueza con el descubrimiento del oro en California, en $1849 .{ }^{12}$

El volumen de rendimiento de los campos petrolíferos estadounidenses, desde unos 2000 barriles en 1859, alcanzó los 3000000 en 1862; decreció hasta 2100000 de barriles en 1864, por los efectos de la saturación inicial del mercado, para luego superar los 3500000 en 1866 . Eso generó una súbita creación de riqueza, acompañada de la formación de cientos de empresas, perforaciones masivas, la activación de miles de buscadores, el seguimiento asiduo por parte de la prensa, en el marco de un frenesí petrolero. En la etapa inicial, la enorme capacidad extractiva, muy superior a la demanda interna, causó una severa contracción en los precios del crudo, ${ }^{13}$ compensada parcialmente por una agresiva política de exportación. ${ }^{14}$

12 Olien y Davids, Oil and Ideology, p. 22.

13 A mediados de la década de 1850 , el poco aceite obtenido de las fuentes superficiales y los pozos de sal del condado de Allegheny, en el suroeste de Pensilvania, se vendía a precios variables, desde 30 hasta 80 dólares por barril (42 galones) de petróleo crudo. Después de que Drake, en agosto de 1859, demostró que el petróleo se podía obtener en abundancia mediante la perforación de pozos, el precio por barril se posicionó en 20 dólares; durante 1860 disminuyó hasta 2 dólares, y siguió reduciéndose hasta alcanzar los 10 centavos en diciembre de 1861, es decir, menos del valor del barril usado para el transporte. Sucesivamente, el precio experimentó una fuerte recuperación, hasta 1866. Hamilton, "Historical oil”, pp. 239-240. 14 United States, Mineral, 1901, pp. 542-543. Las exportaciones 
Todos los elementos estaban puestos para la transmisión internacional del ejemplo estadounidense, favorecida por el hecho de que el petróleo llegó a considerarse un recurso distribuido de forma más "democrática" - frente al carbón - en la lotería de los recursos naturales: un número relativamente amplio de países podían contar con alguna presencia genérica de bitúmenes en el subsuelo. ${ }^{15}$ De hecho, en este momento histórico empezó a difundirse en el exterior el modelo "pennsylvano" para la producción del petróleo en gran escala, basado en la perforación mecanizada, la entubación y la refinación. Es de notar, sin embargo, que dicha difusión se basó esencialmente en el "efecto-demostración”, generado por el auge espectacular de la producción, y en el comercio exterior, por medio de la importación de una cantidad creciente de petróleo en varios países. No hubo, en ese momento, movimiento de empresas o capitales estadounidenses al extranjero, ${ }^{16}$ tanto por las circunstancias de

de petróleo de Estados Unidos, entre los años fiscales 1861-1862 y 1864-1865, se multiplicaron 10 veces en valor, pasando de 1.5 a 15.5 millones de dólares. Foreign Commerce, varios años. En toda la década, la cantidad exportada de crudo estadounidense fue mayor a la de refinado.

${ }^{15}$ Ya en 1865, un popular manual estadounidense de geología, dedicado a los combustibles fósiles, apuntaba que la existencia de fuentes abundantes de petróleo estaba comprobada en China, las Indias Orientales, Suecia, Noruega, Rusia, México, Sudamérica, California y las Antillas. Bowen, Coal, p. 152.

${ }^{16}$ Está documentada, en cambio, la actividad de algunos pioneros estadounidenses en el extranjero, como John McLeod Murphy y John Emery Gowen, ambos exingenieros del ejército. El primero, como se verá, centró sus actividades en México, mientras que Gowen trabajó en los campos petroleros en Azerbaiyán, y posteriormente ofreció sus servicios en Rumania. Hamilton, Americans 1962; Gerali y Riguzzi, “Los inicios”. No sólo el volumen del comercio transoceánico, sino también hechos 
la Guerra de Secesión como por el hecho de que la actividad petrolera nacional ofrecía un campo enorme a la inversión. Además, en esta etapa pionera, la tecnología de extracción no representaba una barrera significativa, por la sencillez y los costos relativamente bajos de aparatos y maquinaria; el reto principal era el de la localización de los puntos donde perforar, tarea para la cual no existían normas definidas. ${ }^{17}$

Tan sólo en el continente americano, la fiebre petrolera llevó a la activación de explotaciones importantes en Ontario (Canadá), hallazgos y concesiones en Ecuador, Perú, Venezuela, así como al renovado interés por el chapopote de Cuba. ${ }^{18}$ Tanto por la cercanía con Estados Unidos, como por la conocida localización de las chapopoteras, México no podía dejar de recibir el contagio del choque (positivo) petrolero.

\section{LA FIEBRE DEL PETRÓLEO EN MÉXICO}

En el lapso de unos años, en coincidencia con la etapa de la Regencia y el Segundo Imperio, se despertó un interés considerable por la búsqueda de petróleo en México, que se reflejó en varias actividades. En el cuadro 1 se exhiben las

como éstos corroboran la tesis de que el sector petróleo moderno asumió desde el principio un significado internacional.

17 Williamson y Daum, The American, pp. 97, 374. Se puede mencionar también que, para mediados de los años sesenta, se había consolidado un amplio mercado de maquinaria usada.

18 Vassiliou, Historical, pp. 116-117; Buriano, Navegando; Moreno, Petroleum, pp. 6-7; Lieuwen, Petroleum, p. 6. En Cuba, un decreto del gobierno español de la isla, en 1859, había ampliado la superficie de las pertenencias asignables para explotar las minas de chapopote, igualándolas a las de carbón. Revista de Jurisprudencia, Administración y Comercio, t. IV, 1859, p. 550. 
principales iniciativas relacionadas con el energético, tanto en el ámbito de los particulares como en el de la legislación.

\section{Cuadro 1}

INICIATIVAS EN TORNO AL PETRÓLEO EN MÉXICO, 1861-1866

\begin{tabular}{|c|c|c|}
\hline Fechas & Actividades & Legislación \\
\hline $1861-1865$ & $\begin{array}{l}\text { Perforaciones y extracción } \\
\text { de pequeñas cantidades en } \\
\text { Guadalupe Hidalgo, Distri- } \\
\text { to Federal }\end{array}$ & - \\
\hline $1863-1864$ & $\begin{array}{l}\text { Tabasco: el cura Gil y Sáenz } \\
\text { localiza un manantial y reco- } \\
\text { lecta el bitumen de las chapo- } \\
\text { poteras }\end{array}$ & - \\
\hline 1865 & $\begin{array}{l}\text { Exploración de John M. Mur- } \\
\text { phy en el istmo de Tehuante- } \\
\text { pec en busca de petróleo }\end{array}$ & $\begin{array}{l}\text { Dos decretos de Maximi- } \\
\text { liano sobre minería, uno en } \\
\text { referencia a la explotación } \\
\text { del petróleo }\end{array}$ \\
\hline $1864-1866$ & $\begin{array}{l}67 \text { denuncios de zonas petro- } \\
\text { líferas }\end{array}$ & $\begin{array}{l}34 \text { concesiones otorgadas } \\
\text { por la Secretaría de Fomento }\end{array}$ \\
\hline
\end{tabular}

FuENTES: Véase texto.

Los primeros episodios que caracterizaron los inicios de una nueva etapa de la actividad petrolífera, dirigida a la explotación del recurso, tuvieron lugar en el Distrito Federal y en Tabasco y estuvieron - curiosa y significativamenteligados a circunstancias y elementos de la religión católica. ${ }^{19}$ En el primer caso, lo crucial fue la existencia conocida de un manantial de bitumen en Guadalupe Hidalgo, alrededor

${ }^{19}$ Eso remite a una condición de embeddedness de la actividad económica en las normas y valores de una sociedad, a la Karl Polanyi. 
de la iglesia de la Colegiata, lo cual difundió la idea de que había algo milagroso, o por lo menos providencial, en la existencia de petróleo en ese punto, lo que motivó una prolongada e insistente búsqueda, más allá de lo que la prueba material pudiera avalar. ${ }^{20}$ En la zona del Tepeyac, durante muchas décadas, mediante la excavación manual se había recolectado un aceite mineral con afloramiento espontáneo, mismo que se utilizaba para usos terapéuticos y rituales. ${ }^{21} \mathrm{~A}$ finales de los años cincuenta, en los alrededores de la Villa de Guadalupe se llevaron a cabo las perforaciones del empresario italiano Sebastián Pane, introductor de la tecnología para perforar pozos artesianos en el Valle de México, pero los hallazgos de bitúmenes fueron mínimos. ${ }^{22}$ Fue en 1861 cuando se registró el denuncio realizado por Joaquín Davis y Compañía, acorde a las Ordenanzas de Minería, para obtener la concesión del terreno y explotar lo que

20 Véase Dr. Atr, Petróleo, pp. 9-11. La reconstrucción que este autor hace de los intentos extractivos de la década de 1860 es imprecisa. Guadalupe Hidalgo era en ese momento una municipalidad del Distrito Federal, y a mediados del siglo xIx, también para celebrar la importancia del santuario allí ubicado, se trazó una pequeña pero costosa línea pionera de ferrocarril que conectara con la ciudad de México. Riguzzi, "Los caminos", p. 53.

${ }^{21}$ Ya a comienzos del siglo xix, el célebre mineralogista Andrés Manuel del Río había publicado la noticia de la nafta que manaba cerca del santuario de Guadalupe. Sánchez Graillet, “Del chapopote”, pp. 178-179. ${ }^{22}$ La Sociedad (30 jul. 1865), p. 2, publicó un remitido de Pane, con la descripción de sus perforaciones previas en la zona del santuario de Guadalupe. Pane, un exilado político liberal, junto con su socio Molteni, a partir de 1853 había obtenido el contrato exclusivo para la perforación de pozos artesianos con el sistema de percusión con herramienta de cable conocido como "método chino". Siglo Diez y Nueve (26 mar. 1853), p. 3. Véase también Pane, Condiciones. Bajo el gobierno de Maximiliano, como se verá, obtuvo una concesión petrolífera en Puebla. 
se definía como una "mina de aceite de petróleo". No hay prueba de que se haya llevado a cabo la extracción de sustancias del subsuelo, si bien el solicitante se opuso a denuncios sucesivos alegando que infringían sus derechos. ${ }^{23}$

A comienzos de 1864, se verificó un nuevo denuncio de criaderos de nafta y petróleo en las inmediaciones de la Colegiata de Guadalupe ("al pie del cerro de Nuestra Señora de Guadalupe”), del que fueron los titulares uno de los geólogos mexicanos más destacados, Antonio del Castillo, un doctor en medicina y un comerciante..$^{24} \mathrm{Su}$ proyecto se caracterizó por un acercamiento de corte científico, basado en la definición precisa de las sustancias y en la presentación de muestras, lo cual se reflejó en la solicitud que acompañaba

${ }^{23}$ El denuncio del criadero en Guadalupe Hidalgo, calificado como "no explotado", se hizo ante el Gobierno del Distrito Federal. La Independencia (24 abr. 1861), p. 4. No tenemos mayor información acerca de las actividades de Davis, salvo el hecho de que en ese momento era un accionista del pequeño ferrocarril México-Chalco. En febrero de 1864, tras publicarse un nuevo denuncio petrolífero en la zona (el de Del Castillo, véase texto abajo), Davis se opuso, alegando que era violatorio de sus derechos preexistentes, como si hubiese efectivamente llevado a cabo labores de explotación. El Pájaro Verde (2 feb. 1864), p. 2. El interés de este personaje por el petróleo parece haberse eclipsado, puesto que en la ola de denuncios mineros y petroleros de 1864-1865 solo figura solicitando la posesión de minas de hierro y carbón. Ministerio de Fomento, Memoria 1865, pp. 354-357.

${ }^{24}$ Sobre Del Castillo, profesor de geología y mineralogía en la Escuela de Minería, véase Morelos, La geología, que sin embargo no menciona su experiencia petrolera. Sus demás socios eran Miguel Heras, doctor en medicina y Vicente Larrea, comerciante y ex tesorero municipal de la ciudad de México. Como representante legal fungía Javier Heras, quien a mediados de 1864 obtuvo un privilegio de patente para introducir en México unos nuevos quemadores para lámparas de petróleo. Ministerio de Fomento, Memoria 1865, p. 428. 
al denuncio: en lugar del "lenguaje anticuado" de las Ordenanzas y sus "jugos de la tierra" se especificaban la nafta y el petróleo como las sustancias presentes en la zona, y se citaban como prueba las muestras recolectadas y depositadas en el gabinete de minerales del Colegio de Minería. ${ }^{25} \mathrm{Al}$ mismo tiempo, este grupo de socios incorporó en sus intereses la tecnología de refinación mediante la asociación con otro científico, el profesor de farmacia Ricardo Egea y Galindo, quien había conseguido del gobierno imperial una patente para la introducción en México "de los procedimientos extranjeros, por los cuales se obtiene aceite de alumbrado" a partir de sustancias bituminosas. El denuncio dio vida a un curioso intento de integración vertical artesanal, diseñada para abarcar extracción, refinación y comercialización del petróleo que, como se verá más adelante, derivó en operaciones de extracción que subsistieron durante algún tiempo. ${ }^{26}$

${ }^{25}$ La Sociedad (21 ene. 1864). Casi al mismo tiempo del denuncio en Guadalupe Hidalgo, Del Castillo estaba trabajando en su "Cuadro de la mineralogía mexicana", en el que desagregaba la familia de los bitúmenes minerales en nafta, chapopote, asfalto, petróleo y maltha. El cuadro, fechado en noviembre de 1864, se publicó en el Boletín de la Sociedad, t. X, 1863-1864, pp. 564-571.

${ }^{26}$ La patente a Egea se asignó en fecha $1^{\text {o }}$ de agosto de 1864 . Ministerio De Fomento, Memoria 1865, p. 428. En los trámites relacionados con la patente, a Egea se le identifica como profesor de farmacia, residente en Veracruz. Su notoriedad científica fue sin embargo en el campo de la cirugía, además de por su oposición al ingreso de mujeres y no titulados en la carrera médica. CARrillo, "Historia", pp. 22-24. Desde mayo de 1864, Egea, los dos Heras y Miguel y Vicente Larrea se habían asociado para formar una casa comercial en Veracruz, Puebla y México, de la que eran parte los expendios de petróleo. La Sociedad (2 sep. 1866), p. 3. Del Castillo no figuraba en esta sociedad comercial, y es probable que su papel haya sido esencialmente el de asesor técnico en la extracción. 
En Tabasco, en 1863, el sacerdote Manuel Gil y Sáenz localizó la mina de petróleo de San Fernando, con el propósito de recolectar el bitumen que fluía de las chapopoteras presentes en los alrededores de la localidad de Tepetitlán. ${ }^{27}$ Antes de explotar los depósitos en la superficie, Gil y Sáenz pretendió conocer la calidad del bitumen extraído, y remitió unos barriles de crudo a Nueva York, para su análisis químico. Los resultados confirmaron que se trataba de un crudo denso, con valor comercial, de manera que el sacerdote emprendió la recolección del fluido. ${ }^{28} \mathrm{El}$ cura, además de alumbrar su iglesia, aparentemente, durante algún tiempo vendió el crudo en la villa de Macuspana para iluminación. Los resultados económicos generados por el criadero de San Fernando fueron insignificantes: se basaron en excavaciones manuales alrededor de pequeños depósitos de superficie, lo cual no podía ser comercialmente viable; y lo reducido de la demanda local y la ausencia de medios de transporte a bajo costo inhibieron cualquier estímulo a la expansión del negocio, de manera que las operaciones se interrumpieron al poco tiempo. Aun así, el significado del episodio tabasqueño trasciende el fracaso comercial puesto que, por primera

${ }^{27}$ Un posible antecedente del interés de Gil y Sáenz lo constituye la iniciativa de algunos comerciantes de Macuspana, que hacia 1857 se asociaron para fabricar barrilitos de hierro y almacenar el aceite mineral que fluía de un manantial cercano y que, desde antaño, se usaba para alumbrar. Por un tiempo, comercializaron el producto en las localidades vecinas. SÁnchez Graillet, "Del chapopote”, p. 89. La fuente de esta información es un manuscrito de 1915, sin autor, en el Archivo de Pemex. No hemos podido encontrar ninguna prueba que respalde esta versión. Sáenz, que fue cura de Macuspana desde 1856, no hace mención de ello en su relato acerca del hallazgo del petróleo. GIL y SÁNEz, "Breve reseña”. ${ }^{28}$ Gil y Sáenz, “Breve reseña”. 
vez, un actor local decidió llevar a cabo el análisis químico del bitumen para comprobar el potencial comercial efectivo del recurso. ${ }^{29}$ De hecho, poco después la zona fue objeto de denuncios petrolíferos.

El interés por las fuentes de petróleo en México despuntó de manera considerable en 1864 y culminó en $1865 .^{30}$ Eso se plasmó, en el primer año, en la realización de 18 denuncios petrolíferos, ubicados en diferentes puntos del país; al año siguiente, el número creció a 47. Por razones fácilmente identificables, ligadas al estado de guerra en el centro del país, el ciclo se extinguió en 1866, cuando sólo se

${ }^{29}$ Gerali y Riguzzi, "Los inicios”. El informe del comisionado para la agricultura de Estados Unidos relativo al año 1864 contiene - curiosamente - el resultado del análisis de dos variedades de "asfalto mexicano": una sólida y una semilíquida, de las que no se especifica la procedencia. El químico responsable afirmó haber realizado las pruebas el año anterior, lo cual coincidiría con el experimento de Gil y Saénz en Tabasco. CommisSiONer of Agriculture, Report, pp. 537-538.

30 Varios observadores externos dieron testimonio de la activación de esta manía petrolera. Véase la nota "Petroleum in Mexico", en Mining and Scientific Press (20 mayo 1865), la principal revista minera de Estados Unidos en ese momento. El secretario de la legación británica en México reportó a su gobierno los denuncios en varios estados, aunque agregó que en muchos de ellos había dudas acerca de la existencia efectiva de petróleo. Middleton, “Report” 1865, p. 234. El cónsul general estadounidense detectó un rasgo especulativo en el asunto, al considerar que el sinnúmero de solicitudes para la explotación de carbón, petróleo y otros minerales difícilmente podrían generar buenos negocios, debido a la distancia de los centros de consumo y los costos de transporte. Commercial Relations 1864-1865, p. 568. Asimismo, un cónsul del gobierno de Maximiliano en Francia, "en vista de los diversos descubrimientos que se están verificando en el Imperio de criaderos de petróleo”, remitió las instrucciones para el manejo del energético en los depósitos urbanos de París. Diario del Imperio (5 ene. 1866), p. 26. 
verificaron dos denuncios. ${ }^{31}$ Adicionalmente, algunos interesados en los denuncios presentaron una solicitud de privilegio para la introducción de tecnologías de depuración y refinación. Al mismo tiempo, el petróleo empezó a importarse en volúmenes crecientes, reflejando la difusión de su uso como iluminante. Desde cero a comienzos de la década, las importaciones de petróleo estadounidense en México pasaron a 80000 galones en 1863-1864 y alcanzaron los 240000 galones en $1865-1866 .{ }^{32}$ De forma paralela a estos desenvolvimientos, el gobierno imperial decretó una serie de reformas en las Ordenanzas de Minas que abarcaba al petróleo, y asentó que su localización y explotación eran de interés nacional. Se trataba de fenómenos inéditos que plantean, necesariamente, la pregunta acerca de la relación

${ }^{31}$ La Memoria del Ministerio de Fomento para el año 1865 consigna los datos relativos a 62 denuncios petrolíferos y afines (chapopote, asfalto, sustancias bituminosas) realizados entre noviembre de 1864 y noviembre de 1865. Ministerio de Fomento, Memoria 1865, pp. 354-359. La consulta del periódico oficial Diario del Imperio y de La Sociedad ha permitido rastrear otros cinco denuncios: tres realizados en el primer semestre de 1864, en la villa de Guadalupe Hidalgo, y dos entre junio y octubre de 1866, en el estado de Hidalgo y en Tlalpan. En total, se trata de 67 denuncios.

32 Foreign Commerce (1864-1866). La cifra suma crudo y refinado. En Mexican Times (13 ene. 1866), p. 2, tras afirmar que la mayoría de los hogares de la capital ya estaba usando petróleo, se vaticinaba que pronto éste reemplazaría a todos los demás aceites vegetales para uso de iluminación en el país entero. En la Ordenanzas de Aduanas de 1856, no se especificaba el petróleo (en ninguna de las denominaciones de la época) dentro de los rubros del arancel, de manera que se le aplicaba el gravamen común a todos los géneros no reconocidos, que era de $30 \%$ sobre su valor de factura. A partir de 1872, la importación de petróleo quedó aún más gravada, con un derecho específico de 9 centavos por kilogramo. 
de este auge petrolero con el ascenso del nuevo orden político, el del Imperio de Maximiliano.

\section{La política de Maximiliano y sus bases}

La bibliografía reciente sobre el Segundo Imperio ha arrojado luz sobre las características de racionalidad administrativa y económica del abanico relativamente amplio de proyectos de modernización planeados e impulsados por el gobierno de Maximiliano, dentro de un esquema de organización centralista del país. ${ }^{33}$ En este marco, transporte y comunicaciones (ferrocarriles, telégrafos, marina mercante), colonización e inmigración, finanzas (bancos y aseguradoras), minería, fueron objeto de atención, disposiciones legislativas y apoyo. ${ }^{34}$ Aunque Maximiliano integró cuerpos consultivos como la Comisión de Hacienda, a la que encargó el estudio de los elementos de riqueza y las necesidades del país, no se puede sino constatar que, en ausencia del poder legislativo, los costos y los tiempos de promulgación de medidas gubernamentales fueron reducidos. Eso llevó en varios casos a un activismo legislativo más nominal que efectivo, que sobrepasaba las capacidades de instrumentación.

El sector minero se consideró estratégico en la economía del Segundo Imperio, no sólo por su importancia tradicional, sino por la perspectiva de revitalizarlo y diversificarlo

33 Acerca de la cultura administrativa y los proyectos de modernización económica del Segundo Imperio véase Pani, Para mexicanizar.

${ }^{34}$ Pani, Para mexicanizar, pp. 270-291; Robert H. Duncan, "Maximilian and Mexico's first steps toward the global marketplace (1864-1866)", ponencia presentada en el Segundo Congreso de la Asociación Mexicana de Historia Económica, 2006. 
mediante la incorporación de los avances científicos y la reforma del marco jurídico. ${ }^{35}$ En particular, las expectativas se enfocaron en el potencial de los recursos minerales que no fueran los tradicionales metales preciosos (plata y oro); desde este punto de vista, el petróleo tenía una importancia análoga a la del carbón, fierro, cobre, cuya existencia parecía poderse comprobar. Ejemplos de esta política imperial para la minería fueron el proyecto de formación de la carta geológica del Imperio y, sobre todo, las adiciones a las Ordenanzas de Minería, con el propósito de elevarlas "a la altura de los adelantos adquiridos en las ciencias de aplicación al arte de las minas, tanto en el orden del derecho cuanto en el científico". En este último caso, el reformismo imperial, más que una aportación autónoma, era heredero del proyecto del ministro de Fomento del gobierno de Ignacio Comonfort, Manuel Siliceo, que consideró una "necesidad absoluta" reformar las Ordenanzas, e instituyó una comisión de expertos para la elaboración de una nueva legislación minera. ${ }^{36}$

Como se ha visto, el efecto demostración del desarrollo acelerado del petróleo en Estados Unidos se difundió con rapidez en el exterior. La cultura administrativa moderniza-

35 "Considerando que el ramo de Minería es uno de los principales del Imperio, y que es necesario y útil protegerlo por todos los medios que le den mayor ensanche y actividad." Ministerio de Fomento, Memoria 1865, Decreto núm. 20, 8 de enero de 1865. El ministro de Fomento de Maximiliano fue el prestigiado ingeniero y empresario minero de Guanajuato, Luis Robles Pezuela.

${ }^{36}$ Boletín de las Leyes, t. V, circular de la Secretaría de Fomento, 20 de abril de 1865, p. 489. Acerca del proyecto de Siliceo en la década anterior, Secretaría de Fomento, Memoria 1857, pp. 80-81. El Ministerio de Fomento se instituyó en 1853, con una fuerte orientación hacia el sector minero. Velasco Ávila et al., Estado, pp. 133-138. 
dora, de la que Maximiliano era portador, no podía no considerar esta influencia, poderosa y relativamente cercana. ${ }^{37}$ Además de ello, hay dos elementos importantes que contribuyen a explicar el interés del emperador por el petróleo. Uno es de naturaleza biográfica, y reside en que en la región de Galicia, parte del Imperio de Austria-Hungría, ya en la década de 1850 la explotación del petróleo se volvió una actividad importante y convirtió a Galicia en una de las principales productoras en Europa. ${ }^{38}$ Maximiliano, cuya formación había incluido el estudio de los recursos del Imperio y que había sido gobernador de un importante distrito, estaba enterado de los beneficios que la extracción de crudo estaba aportando a la economía de su país. Adicionalmente, el jefe de gabinete civil de Maximiliano era un ingeniero minero, el belga Felix Eloin, familiarizado con los desarrollos energéticos fósiles en aquella nación europea. El interés del gobierno imperial por los combustibles minerales se manifestó también en el financiamiento de la exploración de terrenos carboníferos en Coahuila, encargada a un experto ingeniero estadounidense. ${ }^{39}$

37 En ese ámbito, no hubo influencia de la Comisión Científica de México, organizada por Napoleón III, como aval científico y cultural de la intervención francesa. En los estudios geológicos y mineralógicos de la Comisión, el petróleo mexicano no apareció. Azuela, De las minas, pp. 108-114.

${ }^{38}$ Frank, Oil, pp. 48-57. Galicia cubre un área geográfica que cruza los confines actuales de Polonia, Ucrania y Eslovaquia. A partir del Congreso de Viena de 1815, fue parte del Imperio austriaco.

39 Sobre Eloin, véase Académie Royale des Sciences, Biographie, p. 356. Entre 1865 y 1866, el ingeniero Jacob Kuchler, comisionado por Maximiliano, llevó a cabo el reconocimiento de las cuencas de Sabinas y Salinas, en Coahuila, localizando varios mantos de carbón; algunos de 
En realidad, el impacto del choque petrolero estadounidense alcanzó también al gobierno republicano de forma indirecta, mediante el representante del gobierno de Juárez en Washington, Matías Romero, quien alertó en varias ocasiones a sus superiores acerca de la importancia del recurso. En abril de 1865, casi al mismo tiempo que Maximiliano promulgaba su legislación, Romero envió este comunicado a su gobierno:

Habrá llegado a noticia de Ud. que en este país y principalmente en el Estado de Pensylvania se ha descubierto veneros de aceite mineral o petróleo, que están produciendo riquezas fabulosas [...] si la producción sigue como hasta aquí, el aceite sustituirá dentro de poco al carbón de piedra y a la leña y será el único combustible que llegue a usarse. Esta nueva fuente de inmensa riqueza descubierta en este país, ha hecho pensar a los especuladores de mayor espíritu de empresa, que en México debe haber veneros más ricos que los de Pensylvania, cuya teoría parece sostenida por la configuración geológica de la República. ${ }^{40}$

De hecho, Romero mantuvo negociaciones con varios estadounidenses interesados en conseguir concesiones de explotación, que no fructificaron. ${ }^{41}$

El gobierno imperial, por su parte, promulgó su legislación sobre recursos minerales en dos partes. La primera, del 8 de enero de 1865, era un cuerpo bastante simple de seis artículos, relativo a todos los minerales, y que abarcaba los

ellos se explotaron dos décadas después. AGN, SI, c. 34, exp. 81, acuerdo del Ministro de Fomento.

${ }^{40}$ Matías Romero a Ministro de Relaciones Exteriores, Washington, 5 de abril de 1865, en Correspondencia, t. V, p. 192.

${ }^{41}$ Schoonover, Dollars, pp. 268-269. 
siguientes puntos: compromiso del propietario de la mina de no ausentarse sin dejar un apoderado en el lugar de operaciones; las modalidades de difusión de los denuncios; los procedimientos legales en caso de desacuerdo entre el propietario y las autoridades; el potenciamiento de las facultades judiciales de éstas, en relación con las disputas sobre denuncios, para reducir el recurso a los tribunales. ${ }^{42}$ Este decreto estaba dirigido a promover y facilitar la actividad minera, mediante la disminución de los costos de transacción, con la simplificación de los trámites relativos a la solicitud y adjudicación de las concesiones, así como de aquellos para dirimir las disputas: "Buscar un medio de expeditar el curso de los negocios más frecuentes de la minería”, en palabras del secretario de Fomento.

Un segundo segmento de legislación, más detallada y de mayores alcances, se promulgó seis meses más tarde, el 6 julio, y se refirió exclusivamente a minerales no metálicos, entre los cuales, por primera vez, se citaba al petróleo: "haciendo desaparecer las vagas denominaciones de medios minerales, jugos de la tierra, etc., que no pueden ya admitirse en el estado de adelanto que ha alcanzado la ciencia”. Su breve considerando exponía que era necesario fijar las reglas para trabajar el conjunto de sustancias no metálicas, en vista de que las Ordenanzas no las proporcionaban, y del desarrollo que iba tomando su explotación. ${ }^{43}$ El decreto se conformó con 26 artículos, divididos en 19 prevenciones generales y 7 especiales, que tocaban los siguientes aspectos:

\footnotetext{
42 Ministerio de Fomento, Memoria 1865, pp. 347-348.

43 Ministerio de Fomento, Memoria 1865, p. 24; el texto del decreto está en las pp. 348-349.
} 
salvaguarda de la propiedad de los dueños de la superficie, mediante indemnización por daños provocados por la explotación del subsuelo; evaluación del potencial de la mina o criadero por parte de las autoridades como condición de la concesión; cercamiento del perímetro de los yacimientos; fijación de un tamaño estándar para las concesiones que, en el caso del petróleo, se traducía en pertenencias de $1 \mathrm{~km}$ por lado; limitaciones de las concesiones a una sola pertenencia; separación entre concesiones; estándares de seguridad en el laboreo.

Desde el punto de vista del diseño institucional, el decreto de julio constituía un avance notable, en términos de identificación de los recursos denunciables, fijación de las reglas y también en cuanto a control administrativo. En particular, destacaban dos elementos. Por un lado, la mayor extensión de la pertenencia petrolífera respecto a la de los minerales (art. 10) reconocía la diferencia de los depósitos de hidrocarburos, cuya presencia en el subsuelo se distribuía en forma mucho más irregular que la de las vetas metálicas. ${ }^{44}$ Por el otro, el artículo 8 estipulaba que, una vez presentado el denuncio en tiempo y forma, la facultad de otorgar la concesión recaía en la Secretaría de Fomento, centralizando así una materia que había estado previamente en manos de un organismo corporativo, las Diputaciones de Minería. Y estableciendo, de esta forma, una relación entre el Estado,

\footnotetext{
${ }^{44}$ Según las Ordenanzas de Minería, la superficie asignable a los denunciantes era de 200 varas por lado, alrededor de 160-170 metros. Ya en los años cincuenta, el Ministerio de Fomento había asignado concesiones de explotación carbonífera con dimensiones superiores a las prescritas. Secretaría de Fomento, Memoria 1857, p. 83.
} 
mediante la Secretaría de Fomento, y los interesados en las concesiones, en lo que se refiere al petróleo.

Dicho papel de la Secretaría de Fomento asumía además como criterio guía la existencia del recurso denunciado, en escala comercialmente aprovechable: "Si del expediente resultare que no obstante que exista la sustancia registrada, la explotación ha de ser escasa y por corto tiempo, a causa de ser pobre el depósito, la Secretaría de Fomento declarará que no ha lugar a la solicitud".

En este sentido, se introducía en la legislación un elemento importante de salvaguarda de la eficiencia de la explotación, por parte de la autoridad federal, basado en observaciones de tipo científico y en función antiespeculativa. ${ }^{45}$

\section{SEGUNDO IMPERIO Y PETRÓLEO: DECRETOS, DENUNCIOS Y CONCESIONES}

Con base en este análisis, que reconoce la importancia potencial de la legislación de Maximiliano, por los incentivos que ofrecía al desarrollo de la actividad extractiva, resulta relevante entender qué papel ejerció en el desarrollo del interés petrolero en México. ¿Fue útil para estimular, facilitar o consolidar el movimiento de denuncios y concesiones de terrenos petrolíferos? ¿Alentó la realización de inversiones en este sector? De entrada, es posible adelantar que

${ }^{45}$ Valía, en este sentido, el mismo principio que el ministro Robles Pezuela había enunciado respecto a los negocios mineros en general, que "el Estado debe esencialmente poner al abrigo de la rapacidad e inexperiencia de especuladores comunes, porque una especulación de este género requiere conocimientos particulares, una economía y un desinterés de larga duración”. Ministerio de Fomento, Memoria 1865, p. 20. 
la respuesta a estos interrogantes no es unívoca, y necesita diferenciarse por ámbitos específicos. Nuestro análisis se enfocará en tres niveles: los denuncios, las concesiones y las inversiones efectuadas.

\section{Cuadro 2}

DECRETOS MINEROS DE MAXIMILIANO

Y SECUENCIA DE DENUNCIOS PETROLÍFEROS

Decreto de 6 de enero de 1865

Denuncios
Decreto de 7 de julio de 1865

Denuncios

\begin{tabular}{cccc}
\hline Previos & Sucesivos & Previos & Sucesivos \\
\hline 18 & 49 & 58 & 9 \\
\hline
\end{tabular}

Si se considera el conjunto de 67 denuncios realizados en el periodo que va de enero de 1864 hasta finales de 1866, resulta evidente que no se comprueba la hipótesis de que la legislación imperial haya permitido o estimulado el movimiento. Puesto que el segundo decreto, el de julio, es claramente el más relevante, se puede observar que solo una pequeña fracción (13\%) de los denuncios se realizó durante su vigencia; para cuando se promulgó, la búsqueda de zonas petrolíferas había entrado en claro declive, por saturación y luego en respuesta a la creciente incertidumbre política. Incluso si se toma en cuenta el primer decreto, más general y de menor alcance, se observa que no dio vida a la ola de denuncios, puesto que una porción significativa (27\%) se llevó a cabo antes. De hecho, alrededor de una tercera parte de los denuncios (21) se hizo bajo clasificaciones genéricas, que la legislación imperial pretendía reemplazar, porque no 
permitía identificar el recurso a explotar: sustancias bituminosas, betún mineral, o carbón y petróleo juntos. ${ }^{46}$

En cambio, si nos referimos a las concesiones otorgadas, el papel de la política imperial se trasluce de forma significativa, en su calidad de regulador, gracias a la centralización de las decisiones en manos de la Secretaría de Fomento, que se aplicó de facto, aun antes de estar incorporada en un decreto. De los 62 denuncios petrolíferos de los que se conoce el desenlace administrativo (de los 67 totales), sólo 35 fueron aprobados por Fomento y se convirtieron en concesiones. ${ }^{47}$ ¿Qué significa que casi la mitad de las solicitudes hayan sido rechazadas? A diferencia de lo que se afirma en algunos textos, la prueba indica que el gobierno de Maximiliano no distribuyó las concesiones petroleras con facilidad automática. ${ }^{48}$ La hipótesis más lógica es que el criterio de selección enunciado en el decreto del 6 de julio de 1865, relativo a la existencia comprobable del recurso, se haya aplicado, por lo menos como referencia, incluso antes de la entrada en vigor de la ley. Ello se acredita cuando se contrasta la geografía de los denuncios con la de las concesiones.

$\mathrm{Al}$ respecto, el mapa 1 muestra las municipalidades en las que se efectuaron denuncios de criaderos o depósitos de

${ }^{46}$ Cálculos basados en Ministerio de Fomento, Memoria 1865.

47 En 1919, la Secretaría de Industria y Comercio recopiló los datos relativos a la historia de la legislación petrolera en México y a las concesiones otorgadas, entre ellas las del gobierno de Maximiliano. SECretaría DE INDUSTRIA, Documentos, pp. 36-37. En la lista figuran 38 concesiones, pero 3 de ellas, que hemos descontado, se refieren sólo a terrenos carboníferos; quedan, por lo tanto, 35 concesiones.

48 Canudas, Las Venas, t. II, p. 1148, sostiene que Maximiliano, a quien considera poco interesado en los negocios petroleros, "concedía y autorizaba por rutina las solicitudes". 
petróleo, mientras que el mapa 2 señala aquellas en las que el gobierno autorizó las concesiones.

\section{Mapa 1}

\section{DistRITOS CORRESPONDIENTES A LOS DENUNCIOS}

DE ZONAS PETROLÍFERAS ENTRE 1864 Y 1865

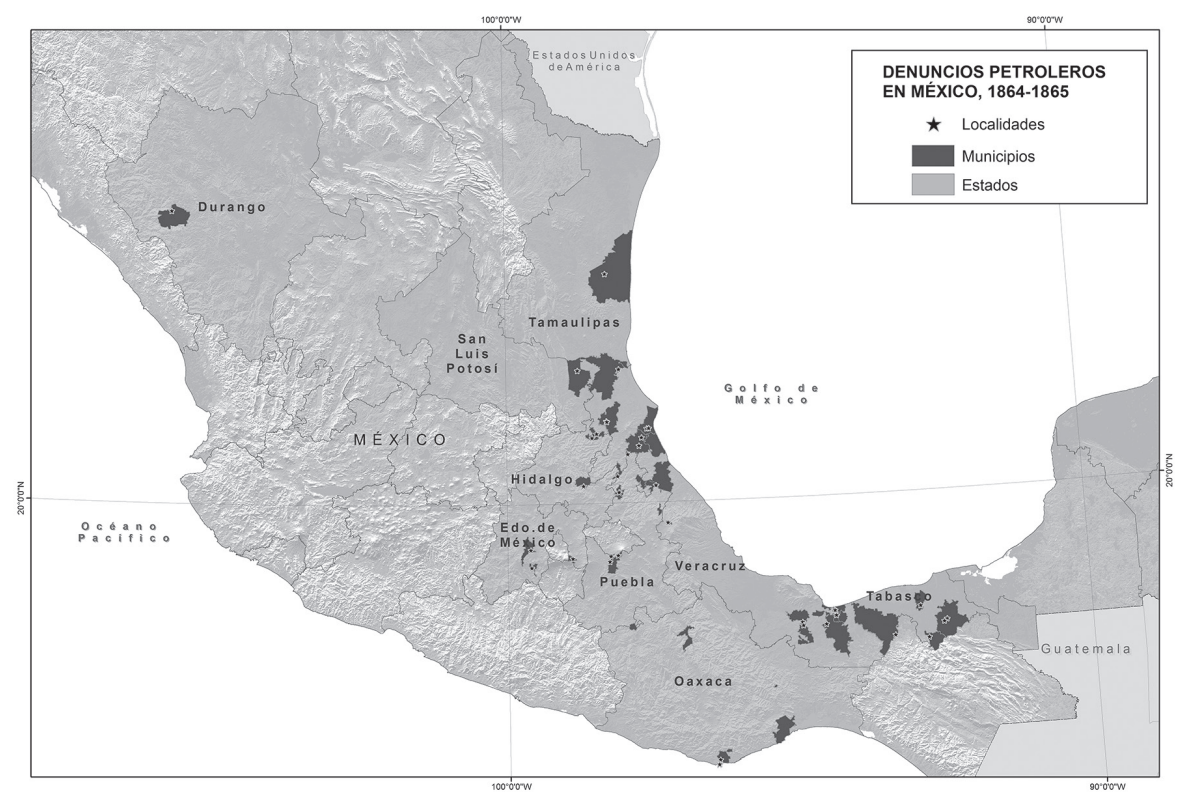

Elaboración gráfica de Nayelli Hernández.

Se aprecia que los denuncios abarcaban nueve estados, con una concentración numérica en el de Veracruz, en el que se distribuían entre varias regiones (norte, centro e istmo), seguido por Puebla, Tabasco y Tamaulipas. 
Mapa 2

DISTRITOS CORRESPONDIENTES A LAS ZONAS

DE LAS 35 CONCESIONES OTORGADAS EN 1864 Y 1865

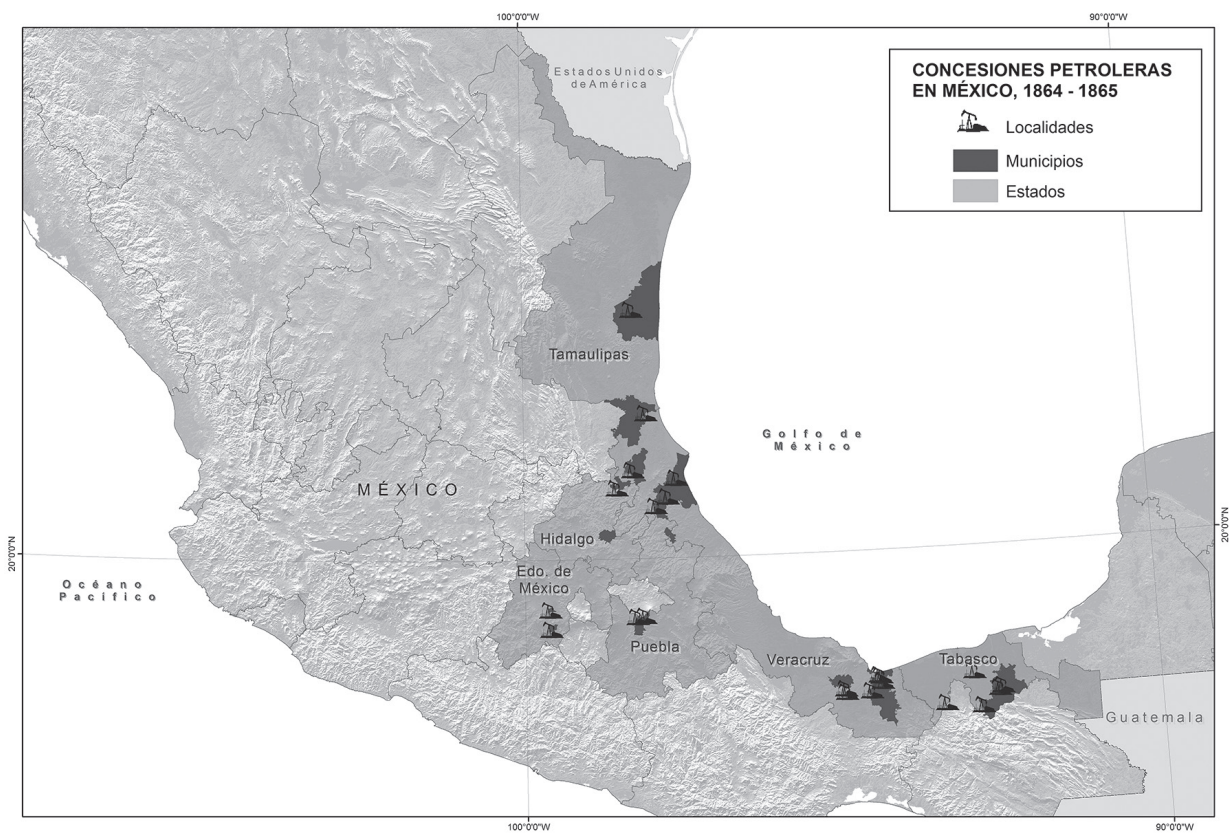

Elaboración gráfica de Nayelli Hernández.

En cuanto a las concesiones, éstas se asignaron sólo en seis entidades, con una lógica geográfica que indica la exclusión de las zonas más alejadas respecto a los principales descubrimientos petrolíferos, tales como Durango, Estado de México, Hidalgo, Oaxaca y San Luis Potosí. Este rasgo se hace más evidente si se cruza el número de denuncios y de concesiones por estado, como se hace en el cuadro 3. 


\section{Cuadro 3}

DENUNCIOS Y CONCESIONES PETROLÍFERAS POR ESTADO

\begin{tabular}{lccccccc}
\hline & VC & VC & VC & & & Otros \\
& norte & centro & Istmo & Tams. & Tab. & Puebla & (5) \\
\hline Denuncios & 11 & 5 & 9 & 7 & 8 & 12 & 10 \\
Concesiones & 8 & 3 & 5 & 5 & 6 & 3 & 2 \\
\hline
\end{tabular}

NotA: $\mathrm{VC}=$ Veracruz.

Fuentes: cálculos basados en Memoria de Fomento 1865.

Hay tres estados - Veracruz, Tamaulipas y Tabascoen los que el porcentaje de concesiones asignadas, sobre los denuncios, fue de $60 \%$ o más; en Puebla de $25 \%$ y en otros cinco estados, el porcentaje fue de $20 \%$. Nuestra hipótesis es que esta diferencia considerable puede atribuirse al estado de los conocimientos disponibles y comprobables empíricamente sobre la localización de petróleo y sustancias afines. En el caso de Veracruz y Tamaulipas, los informes locales acerca de la existencia de aceites minerales se habían convertido en "noticia estadística", como en el caso del área de Tuxpan y de Tecolutla (Papantla). ${ }^{49}$ Además, la visita de inspección del geólogo Del Castillo, comisionado para la formación de la carta geológica del Imperio, había avalado la existencia de formaciones petrolíferas en diferentes puntos

49 Para el distrito de Tuxpan, véanse las menciones del petróleo ("varios extensos manantiales de ese betún negro de un olor penetrante, conocido con el nombre de chapopote") en FAGÉs, Noticias, p. 54; para la región de la Huasteca, Sото, Noticias, p. 196; se trata de un texto publicado en 1869 pero elaborado con información recogida durante una visita de inspección en 1853. Acerca del proceso de conversión de las "noticias del territorio" en "noticias estadísticas", véase Sunyer Martín, "Noticias", pp. 25-37. 
de la Huasteca. ${ }^{50}$ En lo que concierne al Istmo, se contaba con una tradición de conocimiento codificado acerca de la presencia de aceites minerales, procedente de las exploraciones para la localización de una ruta interoceánica. La exploración del ingeniero Cayetano Moro, en 1842; la del Conde Gómez de la Cortina en 1844; la expedición científica de John G. Barnard, del cuerpo de ingenieros de Estados Unidos, y el correspondiente informe Williams de 1852, dieron a conocer, de forma muy sintética, que se habían localizado manantiales de petróleo en la zona, en particular en las localidades de Ixhuatlán y Moloacan. ${ }^{51}$ De forma significativa, en 1865 tuvo lugar, como se verá, la primera exploración científico comercial relativa al petróleo, conducida por el ingeniero estadounidense John McLeod Murphy en Tehuantepec. En cuanto a Tabasco, varias de las concesiones se ubicaban en la zona en donde había tenido lugar la experiencia pionera del sacerdote Gil y Sáenz, y es probable que este elemento haya avalado la conveniencia de la búsqueda. En los demás estados, se debe haber considerado que la presencia de petróleo era un hecho conjetural, extemporáneo o esporádico, que no merecía la protección gubernamental, lo cual se apoyaba en fundamentos geológicos.

50 Ministerio de Fomento, Memoria 1865, p. 27.

${ }^{51}$ Gerali y Riguzzi, “Entender”. El párrafo del informe Williams acerca del petróleo de Moloacan se reproduce de forma textual en el complemento mexicano al Diccionario Universal, publicado en 1856, bajo la dirección del geógrafo Manuel Orozco y Berra. Un relato de viaje de 1860 que gozó de amplia circulación, el del francés Charles Brasseur de Bourbourg, también anotaba la presencia de petróleo en Moloacan. Brasseur, Viaje, p. 61. 
Sin embargo, ello no siempre garantizó un procedimiento administrativo uniforme y menos un resultado eficiente: de esta forma, mientras llegaron a asignarse concesiones en lugares pocos adecuados para la explotación petrolera, como en el Estado de México e Hidalgo, aparentemente se rechazaron algunas solicitudes en localidades con evidencias abundantes de la presencia de bitúmenes, como Temapache (Tuxpan), Aginche y Laguna de Gila (Pánuco) y El Espinal (Papantla). Dos circunstancias plausibles que pueden explicar tales casos, ambas relacionadas con el estado de guerra, son la politización en la asignación de las concesiones, que desfavoreció a los personajes hostiles al régimen imperial, ${ }^{52}$ y la geografía del enfrentamiento militar, que pudo haber impedido el seguimiento de los trámites administrativos en las zonas consideradas. ${ }^{53}$

${ }^{52}$ El denuncio en Temapache lo realizaron Gumesindo Mendoza, farmacéutico, Manuel Medina, médico, y el citado ingeniero Del Castillo. Diario del Imperio, 14 de marzo de 1865, p. 242; CanUdas, Las Venas, t. II, p. 1147. En el transcurso de 1865, la postura de Mendoza se volvió más crítica hacia el régimen, y de hecho acabó por renunciar a su puesto en el Consejo Superior de Salubridad. Diario del Imperio (9 ene. 1866), p. 38. Hay evidencia de que la filiación política de Del Castillo le acarreó problemas con el gobierno imperial; véase Morelos, La geología, p. 57. Es probable que el tercer socio, Medina, haya compartido las ideas republicanas, porque al restablecerse la república, fue diputado local en Hidalgo. Del denuncio del Espinal fue responsable Manuel García Tello, quien había sido diputado federal durante 1861-1862, y quien, a partir de 1869, fue administrador de la aduana de Tuxpan.

${ }^{53}$ En el caso de José O. Forns, denunciante de los terrenos de Gila (o Chila) en la Hacienda Limón, de su propiedad, después de un año de la fecha del denuncio, éste dirigió un ocurso a la autoridad, manifestando que "en atención al estado de guerra en que se encuentra aquella localidad, y no poder dirigirse el interesado a la autoridad correspondiente", el 
Hay un segundo criterio regulador que emerge del análisis de las concesiones de Maximiliano y que verte sobre lo que se puede concebir como el grado de concentración empresarial. El conjunto de 67 denuncios realizados durante el gobierno imperial se caracterizó por estar fuertemente concentrado: tres personas o sociedades fueron responsables de más de $50 \%$ de las solicitudes de explotación de bitúmenes. En particular, Ildefonso López (con 20), Carlos T. Arnoux y Compañía (8) y la sociedad Murphy-Drew (6), presentaron un total de 34 denuncios, mientras que el resto de los denuncios (33) se originó a partir de 26 personas o sociedades. ${ }^{54} \mathrm{Sin}$ embargo, en el caso de los tres personajes mencionados, las concesiones realmente otorgadas fueron 21, con un porcentaje de aprobación, con respecto a los denuncios, de 60, 75 y 50\%, respectivamente. Desde este ángulo, es revelador del empleo de criterios lo que el mismo Maximiliano dictó en referencia a las solicitudes de explotación petrolífera y carbonífera en la Huasteca, por parte de Ildefonso López: "se le concederá la mayor extensión posible que permitan las leyes, después de que se llenen todos los requisitos prevenido en las Ordenanzas del Ramo; pero de ninguna manera el privilegio que solicita". ${ }^{55}$

denuncio debía considerarse en suspenso. En Diario del Imperio (21 mar. 1866), p. 305, se reproduce la comunicación de enero de 1866.

${ }^{54}$ Una tercera parte de los denuncios de López fueron en sociedad con M.O. Paredes, quien a su vez presentó un denuncio de petróleo y otro de carbón, en Veracruz, con Antonio Martínez. Además, tres personas del mismo apellido, Hoquet o Lloquet, denunciaron tres terrenos petrolíferos en la misma zona del estado de Puebla, y podrían considerarse un grupo. Cálculos basados en Ministerio de Fomento, Memoria 1865.

55 AGN, SI, c. 34, exp. 63, Maximiliano a Subsecretario de Fomento, 8 de julio de 1864 . 
Los interesados en el petróleo mexicano: perfiles $y$ actividades

Puesto que la búsqueda de petróleo representaba una actividad del todo nueva en la economía mexicana, es oportuno entender quiénes fueron los interesados en esta innovación durante el gobierno de Maximiliano. ¿Se trataba de inversionistas extranjeros, o propietarios de terrenos con indicios visibles de bitúmenes en el subsuelo? ¿Empresarios mexicanos deseosos de localizar nuevas fuentes de riquezas o intermediarios y especuladores? ¿Con base en qué información y qué conocimientos técnicos acerca del subsuelo persiguieron las concesiones? El propósito es averiguar cuáles eran las capacidades potenciales y la especialización con las que estas figuras contaban para dedicarse al negocio petrolero en México.

De entrada, es posible reconocer que entre los denunciantes en el Segundo Imperio no figuraba ninguno de los comerciantes-financieros-propietarios que integraban los círculos económicos de importancia en México. Si bien los datos acerca de los titulares de los denuncios son relativamente escasos, hemos reconstruido los perfiles y los intereses de 14 de ellos (personas y grupos), que por sí solos concentraron dos terceras partes de los denuncios. Los hemos clasificado según se tratara de actores externos, no arraigados en el país, prescindiendo de su estatus jurídico de nacionalidad, ${ }^{56}$ y actores

${ }^{56}$ En esta clasificación, no tomamos en cuenta el estatus jurídico o la nacionalidad de los personajes, sino el arraigo en la economía mexicana. De esta forma, para los fines de nuestra tipología eran actores domésticos el español Ildefonso López, propietario de haciendas en Tamaulipas y avecindado en México desde los años cuarenta (véase AGN, Cartas de seguridad, vol. 51, exp. 371), el angloespañol José Oriol Forns, originario de 
domésticos, en referencia a personajes cuyas actividades se habían desarrollado por completo en México. Dentro de esta segunda categoría, hemos distinguido entre actores "nacionales", que realizaron denuncios que se ubicaban fuera del área usual de sus operaciones, y locales, cuyos intereses y propiedades eran físicamente cercanos a -o incluso coincidían con- las zonas petrolíferas. En cada caso, se especifican las actividades previas de estos personajes, para establecer su cercanía con el negocio petrolero; su vinculación simultánea con objetivos adicionales, para determinar si el interés por la búsqueda de petróleo era central o si sólo era parte de un cuadro más amplio de proyectos comerciales; y las actividades ligadas al denuncio, para definir si este acto administrativo estuvo acompañado por alguna otra acción. Por último, se detecta si hay pruebas de que los titulares de los denuncios hayan mantenido alguna relación con negocios de hidrocarburos tras la caída del régimen imperial. Los resultados se exponen en el cuadro 4.

La posición en la tipología externo/doméstico no revela diferencias significativas respecto al perfil empresarial de los involucrados. La mayoría de los titulares de denuncios no tenía conocimientos teóricos ni experiencias relacionada con bitúmenes, o incluso con el sector extractivo. Las excepciones relevantes eran las del estadounidense Murphy, el italiano Pane y el mexicano Del Castillo. El primero había participado previamente en misiones de reconocimiento geográfico del Istmo de Tehuantepec, durante las cuales se

Gibraltar y con pasaporte británico, residente desde los años treinta, con lazos matrimoniales en la élite potosina y hacendado. Acerca de Forns, Monroy, Sueños, p. 179, que sólo lo identifica como comerciante español. 


\section{Cuadro 4}

PERFILES EMPRESARIALES Y ACTIVIDADES

DE LOS TITULARES DE DENUNCIOS

\begin{tabular}{|c|c|c|c|c|}
\hline & $\begin{array}{l}\text { Solicitantes y ubicación } \\
\text { del denuncio }\end{array}$ & $\begin{array}{l}\text { Actividades previas/ } \\
\text { intereses paralelos al } \\
\text { denuncio }\end{array}$ & $\begin{array}{l}\text { Actividades } \\
\text { ligadas al } \\
\text { denuncio }\end{array}$ & $\begin{array}{c}\text { Interés } \\
\text { tras } 1867\end{array}$ \\
\hline \multirow{5}{*}{$\mathrm{E}$} & $\begin{array}{c}\text { John M. Murphy- } \\
\text { George Drew (Istmo) }\end{array}$ & $\begin{array}{l}\text { Ingeniero militar } \\
\text { y topógrafo, } \\
\text { comerciante }\end{array}$ & Exploración & Sí \\
\hline & $\begin{array}{c}\text { Charles T. Arnoux } \\
\text { (Tabasco) }\end{array}$ & $\begin{array}{l}\text { /Concesionario de } \\
\text { líneas telegráficas y } \\
\text { ferrocarril urbano }\end{array}$ & $\begin{array}{c}\text { Representante } \\
\text { de intereses } \\
\text { estadounidenses }\end{array}$ & No \\
\hline & $\begin{array}{l}\text { D.R.C. Hoyt } \\
\text { (Istmo) }\end{array}$ & $\begin{array}{l}\text { Cónsul de E.U. en } \\
\text { Minatitlán }\end{array}$ & $\begin{array}{l}\text { Imitación de } \\
\text { Murphy }\end{array}$ & No \\
\hline & $\begin{array}{l}\text { Gabor Naphegui } \\
\text { (Hidalgo) }\end{array}$ & $\begin{array}{c}\text { Contratista, } \\
\text { concesionario de } \\
\text { servicios públicos, } \\
\text { intermediario }\end{array}$ & $\begin{array}{c}\text { Representante } \\
\text { de intereses } \\
\text { estadounidenses }\end{array}$ & No \\
\hline & $\begin{array}{c}\text { J. Morner-E. } \\
\text { Courcillon (Durango) }\end{array}$ & $\begin{array}{l}\text { /Traductor oficial, } \\
\text { concesionario de } \\
\text { servicios públicos }\end{array}$ & N.D. & No \\
\hline \multicolumn{2}{|r|}{$\begin{array}{c}\text { Ildefonso López } \\
\text { y socios (Oaxaca, } \\
\text { Veracruz, Tamaulipas) }\end{array}$} & $\begin{array}{c}\text { Propietario, } \\
\text { intermediario/ } \\
\text { denuncios de } \\
\text { otros minerales; } \\
\text { colonización }\end{array}$ & N.D. & No \\
\hline & $\begin{array}{l}\text { Sebastián Pane } \\
\text { (Puebla) }\end{array}$ & $\begin{array}{c}\text { Perforador de } \\
\text { pozos artesianos/ } \\
\text { denuncios de otros } \\
\text { minerales }\end{array}$ & Mediciones & Sí \\
\hline & $\begin{array}{l}\text { Gumesindo Mendoza- } \\
\text { Manuel Medina- } \\
\text { Antonio del Castillo } \\
\text { (Veracruz) }\end{array}$ & $\begin{array}{c}\text { Farmacéutico- } \\
\text { médico-ingeniero de } \\
\text { minas }\end{array}$ & $\begin{array}{l}\text { Compra de } \\
\text { equipo }\end{array}$ & No \\
\hline
\end{tabular}




\begin{tabular}{|c|c|c|c|c|}
\hline $\begin{array}{c}\text { Solicitantes y ubicación } \\
\text { del denuncio }\end{array}$ & $\begin{array}{c}\text { Actividades previas/ } \\
\text { intereses paralelos al } \\
\text { denuncio }\end{array}$ & $\begin{array}{c}\text { Actividades } \\
\text { ligadas al } \\
\text { denuncio }\end{array}$ & $\begin{array}{c}\text { Interés } \\
\text { tras 1867 }\end{array}$ \\
\hline $\begin{array}{c}\text { José O. Forns } \\
\text { (Tamaulipas) }\end{array}$ & $\begin{array}{c}\text { Propietario de } \\
\text { hacienda en la } \\
\text { zona/proyectos de } \\
\text { colonización }\end{array}$ & $\begin{array}{c}\text { Solicitó un } \\
\text { refrendo; se } \\
\text { opuso a la } \\
\text { patente de } \\
\text { López y socios }\end{array}$ & No \\
\hline $\begin{array}{c}\text { Manuel García Tello } \\
\text { (Veracruz) }\end{array}$ & $\begin{array}{c}\text { Exdiputado-Jefe } \\
\text { militar }\end{array}$ & $\begin{array}{c}\text { No obtuvo la } \\
\text { concesión }\end{array}$ & Sí \\
\hline $\begin{array}{c}\text { José M. Bello y García } \\
\text { (Puebla) }\end{array}$ & $\begin{array}{c}\text { Exdiputado/ } \\
\text { problemas } \\
\text { financieros }\end{array}$ & $\begin{array}{c}\text { No obtuvo la } \\
\text { concesión }\end{array}$ & No \\
\hline $\begin{array}{c}\text { Antonio Gutiérrez } \\
\text { Victory-Tito Rosas } \\
\text { (Veracruz) }\end{array}$ & $\begin{array}{c}\text { Comerciante de } \\
\text { Tampico-ingeniero } \\
\text { de minas }\end{array}$ & N.D. & No \\
\hline $\begin{array}{c}\text { Julián Herrera-José H. } \\
\text { Ramírez (Veracruz) }\end{array}$ & $\begin{array}{c}\text { Autoridad local- } \\
\text { abogado }\end{array}$ & $\begin{array}{c}\text { Visita E.U. } \\
\text { para conseguir } \\
\text { maquinaria; } \\
\text { oposición a la } \\
\text { patente de López } \\
\text { y socios }\end{array}$ & No \\
\hline $\begin{array}{c}\text { Manuel Ortega y } \\
\text { García (Veracruz) }\end{array}$ & Labrador & N.D. & No \\
\hline
\end{tabular}

NotAs: $\mathrm{E}=$ actores externos; $\mathrm{D}=$ Actores domésticos. En la segunda columna, la diagonal (/) separa las actividades ligadas a la trayectoria de los personajes de los intereses de éstos en otros negocios paralelamente al del petróleo. Fuentes: véase el texto. 
habían localizado manantiales de petróleo; como se verá, realizó a su vez una extensa exploración de la zona, en 1865, para localizar los yacimientos y solicitar la posesión, e incluso unos años después volvió a denunciarlos. El segundo era el único con una comprobada experiencia en perforaciones, ligada a los pozos artesianos y también a los intentos mencionados en Guadalupe Hidalgo. Pero, al mismo tiempo que las gestiones petrolíferas, Pane se interesó en denuncios de otras sustancias minerales en otras regiones, además de gestionar un abanico de actividades que iban de los baños de aguas termales a los proyectos de desagüe del Valle de México. Su concesión de petróleo en Puebla no dio vida a operaciones extractivas, aunque se hizo una perforación, sin entubación, y estudios hidroscópicos. ${ }^{57}$ El problema esencial, en este caso, es que se trataba de una localización geológica errónea. Pane, por otra parte, mantuvo su interés en la búsqueda del energético tras el cambio de régimen político, asociándose con un empresario francomexicano, para conseguir franquicias de exploración y explotación. ${ }^{58}$

57 El empresario, que era propietario de la Alberca Pane en la ciudad de México, también solicitó explotar tres depósitos de aguas salinas en el Estado de México, así como dos de carbón de piedra (y bitúmenes anexos) en Guerrero. Ministerio de Fomento, Memoria 1865; Diario del Imperio ( $1^{\circ}$ ene. 1865$)$, p. 3. En cuanto a su concesión en Niscomel, al noroeste de la ciudad de Puebla, Pane aseveró que tras la perforación, hubo una salida de petróleo revuelto con agua, y que los indicios de la formación eran "idénticos a los de Pennsylvania". La Sociedad (30 jul. 1865), p. 2. En realidad, la ausencia de entubación sugiere que la perforación se hizo más bien en busca de agua.

58 En 1869, Pane y Pablo Leataud solicitaron al Congreso una concesión para localizar y explotar el petróleo en varios estados, que les otorgara acceso privilegiado a terrenos federales y exención de derechos. Pero la 
El tercer personaje avezado en la cuestión del petróleo era el ingeniero minero Del Castillo, que venía de la experiencia de la extracción de nafta en Guadalupe Hidalgo, y que se unió a dos socios del ámbito académico para realizar un denuncio en Temapache, una zona con fuerte presencia de chapopoteras en el distrito de Tuxpan. ${ }^{59} \mathrm{El}$ trío, aparentemente, procedió a adquirir útiles y equipo para refinar petróleo, aunque, como se ha visto, no alcanzó a obtener la concesión. Por su parte, Del Castillo abandonó su interés por el negocio petrolífero una vez restablecido el gobierno republicano, al reintegrarse a la actividad docente en el Colegio de Minería. ${ }^{60}$

La mayoría de los interesados en los denuncios eran intermediarios y no inversionistas: no contaban ni con conocimientos ni con capitales para invertir, y representaban a particulares o a compañías. Este era el caso de Carl Arnoux, quien estaba ligado a concesiones para la construcción de

petición de los dos empresarios recibió una respuesta negativa. Siglo Diez y Nueve (31 oct. 1869), p. 1.

59 Se trataba de Gumesindo Mendoza y Manuel Medina, como se explica en la nota 52. La relación de Mendoza con Del Castillo implicaba aspectos jerárquicos ligados a la academia: en una publicación contemporánea al denuncio, este último definía a Mendoza (y al biólogo Alfonso Herrera) como "jóvenes que por su aptitud para el estudio de las ciencias naturales, prometen grandes esperanzas de contribuir eficazmente al conocimiento de la historia natural de nuestro vasto país". Boletín de la Sociedad Mexicana, t. XI, 1865, p. 587. Según la información de CANUDAS, Las Venas, t. II, p. 1147, el tercer socio, Manuel Medina, era un profesor de medicina originario de Huejutla, en la Huasteca hidalguense.

${ }^{60}$ La única referencia está en su discurso de 1868, en la entrega de premios a los alumnos del Colegio de Minería, ante el presidente Juárez; en su alocución, recomendó alentar la explotación de los recursos minerales latentes, como carbón y petróleo. Castillo, Discurso, pp. 5-6. 
líneas telegráficas y ferrocarriles urbanos; del húngaro nacionalizado estadounidense Naphegui, amigo de Santa Anna, que había perdido la concesión para el alumbrado de gas de la capital; del cónsul Hoyt, que en Minatitlán simplemente tuvo noticia de los denuncios de Murphy en el Istmo y se apresuró a imitarlo; y de Morner y Courcillon, personajes de paso en la Corte de Maximiliano. ${ }^{61}$ En condiciones similares estaba un actor doméstico, Ildefonso López, quien además de desempeñarse como apoderado legal en la ciudad de México, poseía una hacienda (San José de las Rusias) cerca del puerto de Tampico, en la que solicitó permiso para explotar los bitúmenes. ${ }^{62}$ Entre finales de 1864 y

${ }^{61}$ Arnoux hizo los denuncios por cuenta de los estadounidenses Theodore Gillespie y John Proctor, que no hemos identificado; Naphegui (también escrito Naphegyi), quien en 1865-1866 trabajaba en Nueva York para la aseguradora Knickerbocker Life, declaró representar a una "compañía americana"; Hoyt trató de interesar a socios en Estados Unidos y, tras haber realizado un denuncio con el gobierno imperial, negoció concesiones también con los republicanos; Morner ostentaba el título de Barón y figuraba en la nómina de la Secretaría de Fomento como traductor, mientras el francés Courcillon, que simultáneamente al denuncio de petróleo, obtuvo el privilegio de organizar la compañía Expreso del Imperio Mexicano, bajo la protección del gobierno imperial, y con atribuciones oficiales en materia de colonización. Ministerio de Fomento, Memoria 1865, pp. 354-356; GerTz, Guide, p. 4; Commercial Relations 1867-1868, pp. 652-653; Almanaque Imperial, p. 85; Diario del Imperio, 20 de mayo de 1865 , pp. 477-478.

${ }^{62}$ En la primera mitad de los años sesenta, López apareció como apoderado legal en varios juicios sobre dinero en la capital, y a principios de 1864 obtuvo con un socio la patente para la introducción en México de una locomotora de acarreo, para trabajo minero, inventada en Estados Unidos. La hacienda San José de las Rusias, de su propiedad, figura en todo recuento de los inicios de la actividad petrolífera en México, aunque con evidencia incierta por lo que concierne a la explotación efectiva. Brown, Petróleo, p. 22. Villarello, Algunas, pp. 19-29, provee un 
mediados de 1865, López fue responsable de una red muy amplia de denuncios de sustancias minerales, localizados en por lo menos cinco estados: los petrolíferos estaban esparcidos en Tamaulipas y Veracruz, en sociedad con Paredes y Cía., y en Oaxaca, mientras que los de carbón y "vetas metálicas" no especificadas, realizados con diferentes socios, se ubicaban en Guerrero y Sinaloa. ${ }^{63}$ Ciertamente, este abanico de intereses se situaba muy por encima de las capacidades administrativas y financieras de López, y sacaba a relucir su papel de intermediario. Pero la pieza central de su estrategia de negocios fue el intento de conseguir la exclusividad legal - por ocho años - de la introducción de los procedimientos de depuración y refinación del petróleo, que López solicitó en unión con un grupo de estadounidenses avecindados en México. ${ }^{64}$ Se trataba de una pretensión, fraseada

estudio geológico de la zona y noticias sobre las sucesivas etapas de la búsqueda de petróleo en la hacienda.

63 El socio de López en varios denuncios petrolíferos, como se ha mencionado, era Manuel Onofre Paredes, propietario de haciendas en el distrito de Tampico, quien se había distinguido por el apoyo al régimen de Maximiliano. La Sociedad (27 ago. 1864), p. 2. Por lo que se refiere a los denuncios de otras sustancias hechos por López, se trataba de solicitudes de explotación de carbón en las cercanías de Culiacán, y de vetas metálicas en el distrito de Iguala, Guerrero. Diario del Imperio (21 mar. 1865), p. 265 (24 mayo 1865), p. 499. En el caso de estas últimas, su denuncio es el único de la época en el que se hace referencia a la conducción de un reconocimiento mineralógico de la zona.

64 Los solicitantes, tras manifestar su intención de “seguir las ideas emitidas por S.M.I. para el engrandecimiento y la prosperidad de este Imperio", se definían "poseedores de los mejores sistemas para el desenvolvimiento industrial de la sustancia bituminosa conocida con el nombre de petróleo", y citaban entre sus objetos la fabricación de keroseno, parafina e hidrocarbonos, y gas para alumbrado. Diario del Imperio (24 ene. 1865), p. 73. En este negocio, y probablemente en varios denuncios, los 
con retórica del engrandecimiento industrial del Imperio, y amparada en la ley de patentes de 1858 , que, con su vaguedad, permitía solicitar el privilegio de introducir de forma exclusiva "descubrimiento o proceso extranjero no conocido en nuestro país", y hubiera equivalido a convertir a los interesados en monopolistas de la venta de los equipos de refinación. La solicitud de privilegio, tras haber generado mucha oposición, fue denegada por parte del gobierno imperial, por tratarse de una invención que ya estaba claramente en el dominio público y que, por lo tanto, no podía ser objeto de patente. ${ }^{65}$ Aun tomando en cuenta este revés, el desvanecimiento tan rápido del interés de López por la búsqueda de petróleo resulta sorpresivo: en 1866 se dedicó a proyectos de colonización y, cuando sus concesiones perdieron validez, con la restauración de la república, sus actividades se reorientaron hacia el perfil más tradicional de la especulación en capitales eclesiásticos nacionalizados o de la elaboración de proyectos ferroviarios aventureros. ${ }^{66}$

socios de López eran inversionistas de pequeña talla: Henry Ward Poole, profesor de inglés en el Colegio de Minería; Hiran Covert, dueño de un almacén de lámparas de petróleo en la capital, y E.M.J. Cune, no identificado. Ward Poole, singular figura de inventor, tenía conocimientos de geología y había participado en una exploración de parte del territorio mexicano organizada por la empresa estadounidense Mexican Coal and Iron, en 1856. Pletcher, “A Prospecting”.

${ }^{65}$ Diario del Imperio (24 abr. 1865), p. 391. La ley de patentes de 1858, promulgada por el gobierno conservador del general Zuloaga, era una copia de la ley francesa. Acerca de sus características, Soberanis, "Catálogo", pp. 113-115.

${ }^{66}$ En 1866, López sometió al gobierno imperial un proyecto de colonización que involucraba los terrenos de su propiedad. AGN, SI, c. 38, exp. 124. Es de notar que su socio Paredes, cotitular en varios denuncios, fue afectado por las fuerzas republicanas, que ocuparon sus haciendas y 
Por lo que concierne a los actores locales, que eran los que tenían el conocimiento más directo de los recursos del territorio, algunos hicieron equipo en los denuncios con personajes de la escena capitalina, que aportaban expertise técnica o legal. Así, Gutiérrez Victory, dueño de un almacén y casa de comisiones en Tampico, se asoció con Tito Rosas, ingeniero topógrafo y de minas. ${ }^{67}$ Julián Herrera, subprefecto de Tantoyuca (Veracruz), se unió al abogado José Hipólito Ramírez, del foro de la capital; ellos manifestaron haber ido a Estados Unidos para estudiar los equipos de refinación y fueron de los opositores a la concesión del privilegio de esta tecnología a Ildefonso López y socios. ${ }^{68}$ Otros actores locales figuraron en cambio solo de manera individual en los denuncios, como en el caso del propietario José O. Forns, que solicitó la explotación de un manantial y una laguna de

confiscaron los animales. La Sociedad (9 oct. 1866). A finales de 1868, López presentó al gobierno de Juárez una propuesta netamente rentista, para expropiar a la compañía inglesa la línea del ferrocarril MéxicoVeracruz y asignarla a una sociedad de comerciantes veracruzanos, que la terminarían gracias al subsidio estatal. Breve Exposición. El Congreso reprobó la iniciativa.

${ }^{67}$ En la lista de denuncios de la Memoria de Fomento, Rosas aparece con el nombre de Sixto, pero la notificación de los denuncios (tanto de petróleo como de mármol) demuestra que se trata de Tito Rosas. Diario del Imperio (1a abr. 1865), p. 356, y (12 junio 1865), p. 551. De hecho, en la misma memoria aparece, con su identidad correcta, entre los ingenieros titulados de la Escuela Imperial de Minas. Ministerio De Fomento, Memoria 1865, pp. 360-361. Tras la caída del Imperio, Rosas se dedicó al dragado de canales y obras de desagüe en el Valle de México. Siglo Diez y Nueve (21 nov. 1868), p. 2. Acerca de Gutiérrez Victory, Directorio, p. 328. ${ }^{68}$ Diario del Imperio (22 dic. 1865), p. 696. Ramírez era hijo del ilustre jurisconsulto José Fernando Ramírez; con ellos figuraba Cayetano Gómez Pérez, que no hemos podido identificar. En Diario del Imperio (15 abr. 1865), p. 359, se publica su oposición a la solicitud de López y socios. 
chapopote en los terrenos de la hacienda Limón, de su propiedad, en las cercanías del río Pánuco; Forns también se opuso a la concesión de López, y posteriormente ofreció al gobierno imperial tierra para propósitos de colonización. ${ }^{69}$ El exdiputado Manuel García Tello fue titular de un denuncio en el cerro del Espinal, en el distrito de Papantla, que no se convirtió en concesión; ${ }^{70}$ pero este personaje fue el que mantuvo la conexión más duradera con el negocio petrolero, mediante su afiliación a dos empresas que en los años sucesivos llevaron a cabo operaciones en la zona. ${ }^{71}$ En un peldaño inferior de la estructura social mexicana estaba Manuel Ortega y García, quien se definía como labrador y que fue

${ }^{69}$ El texano John Brown, que inspeccionó la costa del golfo mexicano en relación con los proyectos de colonización de los exiliados confederados, en 1866 visitó el rancho Aginche, en la hacienda de Forns, dando testimonio de los manantiales de chapopote que fluían en abundancia. Brown, Two Years, pp. 49-50. En su protesta en contra del privilegio tecnológico a López y socios, Forns alegó que "equivaldría a nulificar el objeto de la explotación que supliqué se me hiciera de la laguna y manantial en Aginche”. Diario del Imperio (27 ene. 1865), p. 86. En 1866, ofreció un área de 25 leguas cuadradas de sus tierras al Ministerio de Fomento para el fraccionamiento y la instalación de colonos. La Sociedad (15 feb. 1866), p. 2. 70 Otro exdiputado federal entre los denunciantes fue José Ma. Bello y García, representante del distrito poblano de Teziutlán en 1861, y que efectuó el denuncio en esa zona. El embargo de sus bienes, en 1864, por un pagaré no liquidado de 722 pesos, revela que no tenía medios financieros a su disposición. La Sociedad (27 jul. 1864), p. 3.

${ }^{71}$ La primera fue la Compañía Limitada del Golfo Mexicano para la explotación del petróleo, organizada en 1869. Esta empresa, de vida breve, realizó una perforación alrededor del punto del denuncio de García Tello de 1865. Este último participó como accionista, aportando probablemente la información sobre los criaderos de la zona. Gerali y RiguzzI, "Los inicios", pp. 77-78. La segunda empresa con la que estuvo asociado fue la estadounidense Boston and Mexican Oil, que en los años ochenta perforó varios pozos en el distrito de Tuxpan. 
probablemente el primer gambusino del petróleo, al realizar un denuncio de algunos criaderos en el norte de Puebla y en Papantla (Veracruz), en una zona que cuatro décadas después fue explotada por las empresas petroleras británicas. ${ }^{72}$

En términos generales, el análisis del perfil y las actividades de los involucrados en los denuncios de petróleo durante el Segundo Imperio permite aclarar que la intención efectiva y las capacidades para emprender la explotación fueron muy reducidas, y el negocio consistió principalmente en obtener concesiones para su futura reventa, con la expectativa de que el interés por el subsuelo se incrementara. Eso no se verificó, ni afuera ni adentro: en Estados Unidos, a raíz de las enormes oportunidades petrolíferas disponibles, era muy improbable que los inversionistas se interesaran en las perspectivas remotas del petróleo mexicano; y adentro, el clima de incertidumbre sobre el desenlace de la contienda armada afectó el desenvolvimiento de los negocios. Así, el ciclo petrolero, cuya perspectiva principal no era la explotación autónoma, se cruzó con el ciclo político, con el derrumbe del régimen imperial, lo cual desarticuló un proceso de por sí endeble y azaroso. En conjunto, del total de 33 denunciantes, es altamente probable que solo tres de ellos, a saber Murphy, Pane y García Tello, hayan desarrollado alguna actividad relacionada con el petróleo después del restablecimiento de la república.

72 Diario del Imperio (17 ene. 1865), p. 50. El denuncio que Ortega hizo, por sí y sus tres hijos, no pudo realizarse según los trámites legales adecuados porque el territorio en cuestión se encontraba en manos de "fuerzas disidentes", de manera que un año después se volvió a registrar, con la fecha que le atribuye la Memoria de Fomento. En el segundo registro del denuncio, Ortega agregó un quinto criadero, en la zona de Teziutlán, a los anteriores. Diario del Imperio (24 ene. 1866), p. 117. 
RESULTADOS TANGIBLES DE LA POLÍTICA PETROLERA

Los proyectos petrolíferos gestados en la etapa del Imperio tuvieron una concreción casi nula, en términos de inversión y desarrollo productivos. En el periodo 1864-1867, la única prueba de extracción de petróleo, más allá de las muestras que varios de los denunciantes enviaron a la Secretaría de Fomento, fue la del pozo en las inmediaciones del santuario de la Virgen de Guadalupe. En este caso, bajo la dirección de Del Castillo y socios, hubo perforaciones (no mecánicas) y extracción de bitúmenes durante algunos meses, con resultados muy modestos, que consistieron a lo sumo en algunos centenares de litros de nafta ligera, vendidos al por menor para uso en lámparas o para realizar experimentos quími$\cos { }^{73}$ No queda claro cuál fue el desenlace final del intento, ${ }^{74}$ pero fue suficiente para convencer al principal precursor de la química mexicana, Leopoldo Río de la Loza, acerca de la existencia de una fuente abundante de petróleo en el sitio, y de la conveniencia de explotarla "por ser un producto

${ }^{73}$ La Razón de México (9 feb. 1865), p. 3. En esta nota informativa se menciona un flujo de extracción de 12-14 cuartillos de petróleo al día, equivalentes a 6-7 litros. Al frente de la cantidad minúscula, se subrayaban las cualidades de la sustancia, supuestamente superiores a las del petróleo importado de Estados Unidos. Los medios técnicos de los que se valían los concesionarios eran probablemente de perforación con cable; el periódico citado comentaba que la explotación se realizaba aún en condiciones rudimentarias, "por no haber llegado los aparatos que la facilitarán en abundancia”. En el trabajo del Dr. ATL, Petróleo, pp. 12-13, se menciona un pozo de $70 \mathrm{~m}$ de profundidad.

74 En diciembre de 1865 se disolvió la sociedad mercantil entre Ricardo Egea, Javier y Miguel Heras, y Vicente Larrea. Este último quedó a cargo del expendio de petróleo en la ciudad de México, en el que se vendía la nafta del pozo de Guadalupe. La Sociedad (2 sep. 1866), p. 3. 
natural útil a la industria, la química y la medicina” ${ }^{75}$ Este intento extractivo, ubicado en los alrededores inmediatos de la capital, se diferenciaba y no era representativo de los obstáculos que se presentaban a la explotación en los demás terrenos petrolíferos, puesto que éstos se caracterizaban por la localización en zonas de acceso difícil y costoso, por la falta de caminos y medios de transporte, la lejanía de los centros urbanos y la vegetación muy densa. ${ }^{76}$

Desde este punto de vista, es significativo que la otra experiencia petrolífera concreta fuera en el ámbito de la exploración, mediante el reconocimiento extenso y detallado, por parte de John Murphy, de los hidrocarburos en el Istmo de Tehuantepec. Su viaje de estudio, de cuatro meses, dio vida a una combinación pionera de exploración geográfica, medición topográfica, interpretación geológica y logística del petróleo, que se tradujo en un informe acucioso sobre su existencia en la región y la posibilidad de emprender su explotación. Además, Murphy remitió a Nueva York una amplia selección de muestras de petróleo por analizar y, como se ha visto, llevó a cabo seis denuncios, de los cuales tres se convirtieron en concesiones. ${ }^{77}$

75 "Algunas observaciones sobre la utilidad de las aguas minerales", en El Mexicano (20 sep. 1866), pp. 86-87, Acerca de De la Loza, véase URBán y Aceves, “Leopoldo”. De hecho, el intento se reanudó en los años ochenta del siglo XIX, nuevamente sin resultados.

76 Véase, por ejemplo, la descripción de la visita a los manantiales de chapopote de la laguna de Tampamachoco, al norte de Tuxpan, por parte de un grupo de estadounidenses acompañados por guías locales. El traslado implicó recorrer 20 millas en canoas y caminar unas millas entre pantanos. “Petroleum”, pp. 147-148. En tales condiciones, tan solo la exploración sistemática presentaba dificultades considerables.

77 Murphy, Petroleum. Sobre la exploración de Murphy, remitimos a 
Sin embargo, la noticia registrada por algunos periódicos, en mayo de 1866, de que había empezado la explotación de una mina de petróleo en el Istmo de Tehuantepec, "de abundancia maravillosa", parece responder esencialmente a una operación publicitaria, mediante la cual el principal interesado, Murphy, intentó acaso evitar la caducidad de la concesión, debido a la falta de operaciones. ${ }^{78}$ En realidad, un escollo decisivo fue que los resultados de los análisis químicos del petróleo del Istmo no resultaron alentadores. La sustancia recolectada presentaba dificultades para refinarse a raíz del nivel elevado de agua que contenía; además, en cuanto a rendimiento final, la proporción entre crudo y refinado era sustancialmente baja. Ante el hecho de que el informe no fue suficiente para convencer a los inversionistas potenciales del negocio, a Murphy no le quedaban más opciones que el repliegue. Su informe, pese a que se trataba de un documento impreso, desafortunadamente no tuvo difusión, ni recibió publicidad indirecta o referencias en la

Gerali y Riguzzi, “Entender”. Murphy se entrevistó en Veracruz con el ministro Robles Pezuela y consiguió su apoyo para la localización del petróleo en la región del Istmo. Logró ubicar varios criaderos y denunciarlos, en sociedad con George Drew, un comerciante neoyorquino. A su vez, el Ministerio de Fomento le otorgó tres concesiones, con el plazo de un año, más amplio que el prescrito por las Ordenanzas, para activar la explotación, "en atención a las dificultades que tuvo que vencer el interesado”. AGN, SI, c. 61, exp. 18, 20 de febrero de 1865.

78 La Sociedad (27 mayo 1866), p. 2. Murphy y socios supuestamente podían gozar de la posesión de los criaderos hasta marzo de 1866, después de lo cual, si el trabajo de explotación no arrancaba, la concesión se anularía; de aquí la necesidad de mostrar que había alguna actividad en curso. Además, a principios de mayo de 1866, se registra la presencia de Murphy en México. La Sociedad (18 mayo 1866). 
prensa. ${ }^{79}$ Pero aún en 1870 , convencido de la existencia de petróleo en el Istmo, Murphy volvió a efectuar el denuncio de varios criaderos de petróleo en Minatitlán, mediante representantes. ${ }^{80}$

Si bien, en términos de extracción, los resultados fueron nulos, es probable que se hayan verificado ensayos en el ámbito de la refinación de crudo. Como se ha visto, algunos denunciantes se dedicaron al aprendizaje de tecnología petrolera, y posiblemente a su adquisición. Otro personaje aseveró en 1865 ante el Ministerio de Fomento que en México ya se estaba refinando petróleo, y los datos de importación de crudo desde Estados Unidos avalan esta posibilidad. ${ }^{81}$ En todo caso, el interés por la refinación tuvo cierto desarrollo, como revela la curiosa publicidad que una empresa neoyorquina hizo, en 1866, acerca de la exposición de maquinaria y aparatos para la refinación. ${ }^{82}$ También es

${ }^{79}$ La hipótesis más lógica era que se tratara de un informe comisionado y por lo tanto vinculado por el derecho de propiedad. Gerali y Riguzzi, "Entender".

80 Siglo Diez y Nueve (2 jul. 1870), p. 3. Sin embargo, al poco tiempo Murphy falleció.

${ }^{81}$ Diario del Imperio (27 mar. 1865), p. 288. El declarante era el francés Francisco Bardet, en su protesta contra la patente de introducción solicitada por Ildefonso López y socios. En el trienio julio 1863-junio 1866, las exportaciones de petróleo de Estados Unidos a México revelan proporciones balanceadas entre crudo y refinado. De no existir refinadores, no se explica la introducción de las cantidades de crudo. Foreign Commerce, varios años.

${ }^{82} \mathrm{El}$ anuncio, que se publicó durante dos meses en la prensa capitalina, estaba firmado por la "Compañía de petróleo de Nueva York", y decía que se permitiría el acceso del público a su fábrica, en ciertos horarios y mediante venta de boletos. La Sociedad (14 dic. 1866), p. 3. No hemos podido identificar la empresa a la que se refiere el anuncio, de manera que 
posible citar la experiencia de la Mexican Gas Company, la empresa británica de gas que obtuvo la concesión de Maximiliano para ofrecer servicio de alumbrado, y que a finales de 1866 utilizó ciertas cantidades de chapopote mexicano para la producción de gas petróleo. ${ }^{83}$

Por lo que se refiere a la coyuntura política, como es bien sabido, los proyectos mineros de Maximiliano se estrellaron con las circunstancias de la guerra en México y la progresiva pérdida de apoyo externo (por el retiro de las tropas francesas y la falta de reconocimiento estadounidense), que finalmente llevaron al triunfo del bando republicano y al fusilamiento de Maximiliano. ${ }^{84}$ Después de la caída del gobierno imperial, el gobierno de Juárez invalidó todas las concesiones y, sobre todo, abrogó la legislación relativa al subsuelo, de manera que las antiguas Ordenanzas de Minería de 1783 volvieron a ser el marco regulatorio formal para la cuestiones de petróleo, con consecuencias ciertamente no alentadoras. El aspecto más relevante en el regreso a la situación preexistente residió en la descentralización de las concesiones petrolíferas, que sustrajo el asunto a la Secretaría de Fomento y lo devolvió a manos de los gobernadores estatales, alejándolo así de la agenda económica e informativa

no es posible asentar si se trataba de las visitas a la planta en Nueva York o de una exhibición en México.

83 Gore, "Substitutes", p. 71. La compañía planeaba utilizar el carbón como materia prima, pero la falta de conclusión de la línea del ferrocarril México-Veracruz lo impidió.

${ }^{84}$ Maximiliano fue enjuiciado en Querétaro, en donde había establecido su último bastión. La ciudad aún utilizaba manteca de cerdo para el alumbrado público, pero el teatro en el que se desarrolló el juicio al exemperador se iluminó con lámparas de petróleo. Véase Ratz, Tras las huellas, pp. 106, 198. 
nacional. Si bien ello se debía a un criterio político, el de desconocer la validez de los actos del Segundo Imperio, hay que subrayar que su aplicación no fue uniforme, como indica el hecho de que al ferrocarril México-Veracruz (Mexican Railway), que ostentaba el título de "Imperial", y al Banco de Londres y México, Juárez permitió la continuidad con las concesiones o licencias otorgadas por la administración imperial..$^{85}$ Evidentemente, transporte y finanzas resultaban mucho más cruciales que la incierta explotación del petróleo. Aun así, un contenido de la legislación imperial parece haberse filtrado, incorporado en el derecho minero consuetudinario; según informó el prestigiado especialista Santiago Ramírez, la dimensión de la pertenencia de petróleo de $1 \mathrm{~km}$ por lado, fijada en el decreto de 1865 , pese a no estar vigente, "está admitida como doctrina, y sus preceptos observados por la costumbre". ${ }^{86}$

Apenas restablecida la república, el político liberal Gabino Bustamante intentó trazar cierta continuidad, al escribir que el petróleo abundaba en México, "si debemos dar crédito a las repetidas denuncias que de diversos criaderos de este aceite mineral hemos estado viendo publicarse en todos los periódicos de cuatro o cinco años a esta parte". ${ }^{87}$ Pero

${ }^{85}$ Acerca del debate jurídico sobre la validez de los actos del Imperio, véanse las precisiones de REICH, "El legado".

${ }^{86}$ Ramírez, Noticia, p. 211. Sin embargo, la supervivencia de esta norma no debió ser tan explícita, porque siguió habiendo críticas a las Ordenanzas, por el vacío acerca del tamaño de las pertenencias en el caso del carbón y el petróleo. Véase la opinión del periódico de jurisprudencia $E l$ Foro (22 dic. 1877), p. 485.

87 Monitor Republicano (20 dic. 1867), p. 1. Obviamente, Bustamante no hacía mención del contexto político administrativo en que se había generado el fenómeno. 
la señal que el gobierno republicano lanzó fue que la búsqueda de petróleo no era una cuestión de importancia, y que no requería incentivos o facilitaciones, y más bien tenía que ser objeto de gravamen fiscal. ${ }^{88} \mathrm{La}$ Memoria de $1868 \mathrm{de}$ la Secretaría de Fomento, de forma reveladora, tras apuntar la existencia de "abundantes criaderos de petróleo", no mencionaba la existencia del crudo en las regiones objeto de concesiones por el gobierno imperial (Veracruz, Tamaulipas, Tabasco), sino sólo en Oaxaca, el Distrito Federal y Puebla, zonas rechazadas o marginales en las concesiones de Maximiliano, y, además, carecientes de petróleo.$^{89} \mathrm{Y}$ en 1873 , cuando un grupo de diputados propuso una iniciativa de ley para definir la especificidad de las concesiones petrolíferas, el Congreso la envió a la "congeladora", sin siquiera tomarla en cuenta. ${ }^{90}$

Sin embargo, casi todos los denuncios y las - pocasiniciativas de exploración y perforación de las dos décadas siguientes tenían relación con el mapa del petróleo que emergió entre 1864 y 1865. Un ejemplo significativo son los sitios de la cuenca del río Pánuco, cerca de Tuxpan, y los de la zona del Espinal, en el distrito de Papantla. En los años ochenta y noventa ellos fueron el centro de importantes operaciones petrolíferas promovidas por empresas estadouni-

${ }^{88}$ En agosto de 1867, la Secretaría de Hacienda, dirigió una circular a las jefaturas en los estados, solicitando datos sobre la existencia de criaderos de carbón y petróleo, para computarlos entre las fuentes de riqueza del erario federal. Legislación Mexicana, t. X, doc. 6082, p. 69.

${ }^{89}$ Ministerio de Fomento, Memoria 1867-1868, pp. 45 y 59. En las Memorias sucesivas, relativas a los años 1868-1869, 1873 y 1876-1877, el tema del petróleo ni siquiera se menciona.

90 Diario de los Debates de la Cámara de Diputados, Séptimo Congreso, t. I, p. 471. 
denses y británicas, aunque sin éxito. Hasta que, casi medio siglo después de los denuncios imperiales, las mismas áreas tuvieron un papel clave en el auge del petróleo en México, que llevó al país a la corta lista de los países exportadores.

\section{CONCLUSIONES}

La experiencia petrolífera de mediados de la década de 1860 surgió como contagio del auge de Pennsylvania, pero no produjo resultados desde el punto de vista económico. Su importancia, sin embargo, no se puede soslayar porque la ola de denuncios, si bien no resultó en un volumen de producción, sirvió para ubicar los recursos disponibles y colocarlos en el escenario de los proyectos económicos potenciales. Ello no sólo atrajo en su momento la atención de particulares y gobernantes, sino que gracias a la centralización de la información constituyó un acervo de puntos y localidades petrolíferas destinado a durar. Por primera vez, se generó una atención nacional que tomaba nota de la existencia e importancia del petróleo y proveía elementos jurídicos para facilitar su explotación. De hecho, casi todas las - pocasiniciativas de exploración y perforación de las dos décadas siguientes tenían relación con el mapa de hidrocarburos que emergió en esos años.

En México, la actividad petrolífera constituía en aquel entonces algo realmente novedoso, una frontera social y tecnológicamente alejada de la tradición de los conocimientos y los usos locales del chapopote, pero también de las prácticas mineras de la plata. Empresarios, científicos y autoridades, desconocían los términos económicos y técnicos de la nueva industria y, solo con contadas excepciones, los protagonistas 
de los denuncios petrolíferos no planeaban explotarlos con sus recursos. Las iniciativas se basaron en expectativas simplistas del naciente sector, en las que las noticias del auge de las exportaciones petroleras de Estados Unidos alimentaban la idea de rápidos y fáciles beneficios. En realidad, "hacer aceite" implicaba una inversión inicial en maquinaria y mano de obra calificada, y, sobre todo, la perforación de un pozo en una zona considerada favorable no ofrecía ninguna garantía de éxito. La propia industria estadounidense - cuya producción de petróleo se expresaba en millones de barriles al año - tenía sus raíces en la ruina de centenares de Wildcatters que, por falta de habilidad y suerte, fracasaron en sus intentos. En ese momento, el saber científico, no sólo de México, expresaba incertidumbre sobre el petróleo. En la comunidad geológica internacional circulaban muchas especulaciones sobre su origen y disposición en el subsuelo, que no proporcionaban beneficios para el desarrollo de la industria. En México, los rezagos de empresarios y científicos se vieron compensados en parte por una legislación relativamente vanguardista para esos años, dirigida a desalentar la utilización especulativa de las concesiones y a encauzarlas hacia la explotación efectiva del subsuelo. En este sentido, el papel del estado en la activación y protección del nuevo sector iba a ser de especial importancia. Sin embargo, la política sucesiva de los republicanos al respecto fue una no política, que sólo canceló las medidas de Maximiliano, e ignoró sustancialmente la cuestión del petróleo durante casi dos décadas; hasta que, en 1884, el gobierno federal retomó la centralización de las decisiones sobre el subsuelo, mediante el Código de Minería, pero abandonando, de forma súbita, el marco regulatorio regalista y adoptando el régimen de la 
accesión. En conjunto, el momento petrolífero fue una vertiente secundaria en la experiencia económica y política del Segundo Imperio, pero su relevancia es mucho mayor para la trayectoria del petróleo en México.

\section{SIGLAS Y REFERENCIAS}

AGN, SI Archivo General de la Nación, ramo Segundo Imperio, México.

Académie Royale des Sciences d’Outre-Mer

Biographie Belge d'Outre-Mer, Bruselas, 1968, t. VI.

Almanaque

Almanaque Imperial para el año 1866, México, Tipografía de J.M. Lara, 1866.

Álvarez de la Borda, Joel

Crónica del petróleo en México: de 1863 a nuestros días, México, Pemex, 2006.

Azuela, Luz Fernanda

De las minas al laboratorio: la demarcación de la geología en la Escuela Nacional de Ingenieros (1795-1895), México, Universidad Nacional Autónoma de México, Instituto de Geografía, 2006.

BLACK, Brian C.

Crude Reality. Petroleum in World History, Lanham, Md., Rowman and Littlefield, 2012.

Bowen, Eli

Coal or Coal Oil; or, The Geology of the Earth. Being a Popular Description of Minerals and Mineral Combustibles, Filadelfia, T. B. Peterson, 1865. 
Brasseur de Bourbourg, Charles

Viaje por el istmo de Tehuantepec, México, Fondo de Cultura Económica, 1984.

Breve Exposición

Breve Exposición del Proyecto de la Compañia Mexicana para la construcción del Ferrocarril entre México y Veracruz, México, F. Díaz, de León y Santiago White impresores, 1868.

BRICE, William R.

Myth, Legend, Reality; Edwin Laurentine Drake and the Early Oil Industry, Oil City, Penn., Oil Region Alliance, 2009.

Brown, John T.

Two Years in Mexico. Or the Emigrant's Friend, Galveston, Galveston News, 1867.

Brown, Jonathan

Petróleo y revolución en México, México, Siglo Veintiuno editores, 1998.

Buriano, Ana María

Navegando en la borrasca. Construir la nación de la fe en el mundo de la impiedad, Ecuador, 1860-1875, México, Instituto de Investigaciones Dr. José María Luis Mora, 2008.

Canudas Sandoval, Enrique

Las venas de plata en la historia de México. Sintesis de historia económica, siglo XIX, México, Utopía, 2005, vol. 2.

Carrillo, Ana María

“Historia, Mujeres y farmacia”, Fem, 23: 194 (1999), pp. 22-24.

Castillo, Antonio del

Discurso pronunciado en la distribución de premios a los alumnos del Colegio Nacional de Minería, México, Imprenta del Gobierno en Palacio, 1868. 
Commercial Relations 1864-1865

Commercial Relations of the United States with Foreign $\mathrm{Na}$ tions, for the Year Ended September 30, 1865, Washington, Government Printing Office, 1866.

Commercial Relations 1867-1868

Commercial Relations of the United States with Foreign $\mathrm{Na}$ tions, for the Year Ended September 30, 1868, Washington, Government Printing Office, 1869.

Commissioner of Agriculture

Report of the ... for the Year 1864, Washington, Government Printing Office, 1864.

Correspondencia

Correspondencia de la legación mexicana en Washington durante la intervención extranjera, México, Imprenta del Gobierno, 1871, t. V.

Directorio

Directorio del Comercio del Imperio Mexicano para el año de 1867, México, E. Maillefert, 1867.

Dr. Atr (Gerardo Murillo)

Petróleo en el Valle de Méjico: una golden line en la altiplanicie de Anábuac, México, Polis, 1938.

FAGÉs, Eduardo

Noticias estadísticas del Departamento de Tuxpan, Puebla, Imprenta de José Ma. Macías, 1854.

Forbes, Robert J.

Studies in Early Petroleum Industry, Leiden, E. J. Brill, 1958.

Foreign Commerce and Navigation of the United States

Foreign Commerce and Navigation of the United States (varios años, 1860-1866), Washington, Government Printing Office. 
Frank, Alison Fleig

Oil Empire: Visions of Prosperity in Austrian Galicia, Cambridge, Mass., Harvard University Press, 2005.

Galeana, Patricia (coord.)

El Imperio napoleónico y la monarquía en México, México, Senado de la República, Siglo Veintiuno editores, 2012.

García Cubas, Antonio

Atlas geográfico, estadístico e histórico de la República Mexicana, México, Miguel Ángel Porrúa, 1989 (facsimilar de 1858).

Gerali, Francesco

"Scientific maturation and production modernization; notes on the Italian oil industry in the xix Century", en Oil Industry History, 11: 1 (2012), pp. 89-108.

"Environment, economy, politics and technology. A brief analysis on Mexican petroleum up to early $20^{\text {th }}$ century", en Oil Industry Journal, 13 (2013), pp. 237-260.

Gerali, Francesco y Paolo Riguzzi

"Los inicios de la actividad petrolera en México, 1863-1874: una nueva cronología y elementos de balance", en Boletín del Archivo Histórico de Petróleos Mexicanos, 13 (2013), pp. 63-87.

"Entender la naturaleza para crear una industria. El petróleo en la exploración de John McLeod Murphy en el istmo de Tehuantepec, 1865”, en Asclepio, Madrid [en prensa].

GerTz, Janet Elaine

Guide to the Gabor Naphegyi Papers, Yale University Press, 1983 (en http://drs.library.yale.edu/fedora/get/mssa:ms.1155/ PDF, consultado el 18 de septiembre de 2014).

Gil y SÁenz, Manuel

"Breve reseña histórica de como descubrí la mina de petróleo o gas que está cerca de San Fernando, perteneciente a esta municipalidad de Macuspana”, en Valdemar Álvarez Reyes 
(comp.), Pbro. Manuel Gil y Sáenz: Descubridor del petróleo en Macuspana, Ayuntamiento de Macuspana, 1989.

GonzÁlez, María del Refugio (ed.)

Ordenanzas de la minería de la Nueva España formadas y propuestas por su real tribunal, México, Universidad Nacional Autónoma de México, 1996.

Gore, Henry

"Substitutes for coal in the production of illuminating oil", en Report of the Proceedings of the Tenth Meeting of British Association of Gas Managers, Londres, 1873, pp. 68-79.

Hamilton, Charles Walter

Americans and Oil in the Middle East, Houston, Gulf Publishing, 1962.

Hamilton, James D.

"Historical oil shocks", en R. E. Parker y R. M. Whaples (eds.), Routledge Handbook of Major Events in Economic History, Londres, Nueva York, Routledge, 2013.

Kuntz, Sandra y Paolo Riguzzi (coords).

Ferrocarriles y vida económica en México (1850-1950). Del surgimiento tardio al decaimiento precoz, México, El Colegio Mexiquense, Universidad Autónoma Metropolitana, 1995.

Lieuwen, Edwin

Petroleum in Venezuela: A History, Berkeley, University of California Press, 1954.

Mazadiego Martínez, Luis Felipe, Octavio Puche Riart y José E. Ortiz Menéndez

"Information about Petroleum in America Prior to the Nineteenth Century”, en OrTiz et al. (eds.), 2011.

Meade, Joaquín

La Huasteca veracruzana, México, Citlaltépetl, 1962, 2 vols. 
Middleton, A.

"Report by Mr. Middleton, HBm's Secretary of Legation on the Trade and General Statistics of the Mexican Empire", en Reports by Her Majesty Secretaries of Embassy and Legation on the Manufactures, Commerce, $\mathcal{E}$, of the Countries in which They Reside, núm. 11, Londres, Harrison E Sons, 1866.

Ministerio de Fomento

Memoria presentada a S.M. el Emperador por el Ministro de Fomento Luis Robles Pezuela de los trabajos ejecutados el año de 1865, México, Imprenta de J. M. Andrade y F. Escalante, 1866 .

Memoria de Fomento, colonización industria y comercio, México, Imprenta del Gobierno, 1868.

Monroy, María Isabel

Sueños, tentativas y posibilidades: extranjeros en San Luis Potosí, 1821-1845, México, El Colegio de San Luis, Archivo Histórico del Estado de San Luis Potosí, 2004.

Morelos, Lucero

La geología mexicana en el siglo XIX. Una revisión histórica de la obra de Antonio del Castillo, Santiago Ramírez y Mariano Bárcena, México, Plaza y Valdés, 2012.

Moreno, Federico

Petroleum in Peru. From an Industrial Point of View, Lima, F. Masias \& Co., 1891.

Murphy, John McLeod

Petroleum in Mexico, Nueva York, s.p.i., 1865.

Olien, Roger M. y Diana Davids Olien

Oil and Ideology: The Cultural Creation of the American Petroleum Industry, University of North Carolina Press, 2000. 


\section{Ordenanzas}

Ordenanzas de minería de la Nueva España formadas y propuestas por su real tribunal, estudio y edición de María del Refugio González, México, Universidad Nacional Autónoma de México, 1996.

OrTiz, J. E. et al. (eds.)

History of Research in Mineral Resources, Madrid, Instituto Geológico y Minero de España, 2011.

Pane, Sebastián

Condiciones del sondaje para el establecimiento de pozos artesianos, pozos absorbentes y busca de metales, afuera del Valle de México, México, Ignacio Cumplido, 1857.

PANI, Erika

Para mexicanizar el Segundo Imperio: el imaginario político de los imperialistas, México, El Colegio de México, Instituto de Investigaciones Dr. José María Luis Mora, 2001.

Pérez Hernández, José María

Estadística general de la República Mexicana, Guadalajara, 1862.

"Petroleum"

"Petroleum Wells in Mexico", en American Journal of Science and Arts, XLVI (1868), pp. 147-148.

Pletcher, David M.

"A Prospecting Expedition across Central Mexico, 18561857”, en Pacific Historical Review, 21: 1 (1952), pp. 21-41.

Ramírez, Santiago

Noticia histórica de la riqueza minera de México y de su actual estado de explotación, México, Oficina Tipográfica de la Secretaría de Fomento, 1884. 
Ratz, Konrad

Tras las buellas de un desconocido: nuevos datos y aspectos de Maximiliano de Habsburgo, México, Conaculta, Siglo Veintiuno editores, 2008.

ReIch, Peter

"El legado del Segundo Imperio Mexicano en las revistas de jurisprudencia, 1868-1900”, en GalEANA (coord.), 2012, pp. 367-380.

Ribera Carbó, Eulalia, Héctor Mendoza Vargas y Pere Sunyer (coords.)

La integración del territorio en una idea de Estado. México y Brasil, 1821-1946, México, Universidad Nacional Autónoma de México, Instituto de Geografía, Instituto de Investigaciones Dr. José María Luis Mora, 2007.

Riguzzi, Paolo

"Los caminos del atraso. Tecnología, instituciones e inversiones en los ferrocarriles mexicanos, 1850-1899", en KunTz y Riguzzi (coords.), 1995.

Sánchez Graillet, Luis Avelino

"Del chapopote al petróleo en México: historia de la construcción de una entidad 'natural' a partir de una entidad cultural", tesis de maestría en historia, México, Universidad Nacional Autónoma de México, 2009.

Schoonover, Thomas

Dollars over Dominion. The Triumph of Liberalism in Mexican-United States Relations, 1861-1867, Baton Rouge, Louisiana State University Press, 1978.

Secretaría de Fomento

Memoria escrita por el Ministro del ramo, el C. Manuel Siliceo, México, 1857. 
Secretaría de Industria, Comercio y Trabajo

Documentos relacionados con la legislación petrolera mexicana, México, Dirección de Talleres Gráficos, 1919.

Soberanis Carrillo, Juan Alberto

"Catálogo de patentes de invención en México durante el siglo XIX (1840-1900). Ensayo de interpretación sobre el proceso de industrialización en el México decimonónico", tesis de licenciatura, México, Universidad Nacional Autónoma de México, 1989.

Soto, Manuel F.

Noticias estadísticas de la Huasteca y de una parte de la Sierra Alta formadas en el año de 1853, México, J. M. Sandoval, 1869.

Sunyer Martín, Pere

"Noticias del territorio. La agricultura en México entre 1821 y 1873 ”, en Ribera Carbó, Mendoza Vargas y Sunyer (coords.), 2007.

United States Geological Survey

Mineral Resources of the United States. Calendar Year 1900, Washington D. C., Government Printing Office, 1901.

Urbán Martínez, Guadalupe Araceli y Patricia Elena Aceves

Pastrana

"Leopoldo Río de la Loza en la institucionalización de la química mexicana”, en Journal of the Mexican Chemical Society, 45: 1 (2001), pp. 35-39.

Vassiliou, M.S.

Historical Dictionary of the Petroleum Industry, Lanham, MD, Scarecrow Press, 2009.

Velasco Ávila, Cuauhtémoc, Eduardo Flores Clair, Alma Parra Campos y Édgar Gutiérrez López

Estado y minería en México (1767-1910), México, Fondo de Cultura Económica, Instituto Nacional de Antropología e Historia, 1988. 
Villarello, Juan

Algunas regiones petrolíferas mexicanas, México, Imprenta de la Secretaría de Fomento, 1908.

Williamson, Harold F. y Arnold Daum

The American Petroleum Industry. The Age of Illumination 1850-1899, Evanston, Northwestern University Press, 1959.

Hemerografía

Boletin de la Sociedad mexicana de Geografía y Estadística, 1858-1867.

Diario del Imperio, 1864-1867.

La Independencia, 1861.

El Mexicano, 1866.

Mining and Scientific Press (San Francisco), 1864-1866.

El Monitor Republicano, 1867.

El Pájaro Verde, 1865-1867.

La Razón de México, 1864-1865.

El Siglo Diez y Nueve, 1867-1868.

La Sociedad, 1863-1866. 